\title{
Novel therapeutic approaches for the management of cystic fibrosis
}

\author{
Ryan Jaques, Arslan Shakeel, Cameron Hoyle \\ Centre for Atherothrombosis and Metabolic Disease, Hull York Medical School, University of Hull, UK
}

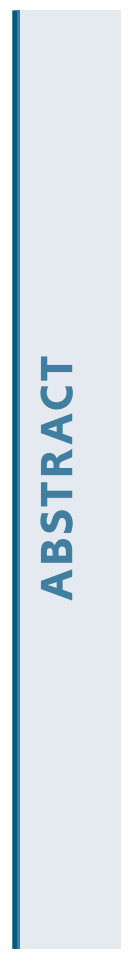

\begin{abstract}
Cystic fibrosis (CF) is a genetic condition characterised by the build-up of thick, sticky mucus that can damage many of the body's organs. It is a life-long disease that results in a shortened life expectancy, often due to the progression of advanced lung disease. Treatment has previously targeted the downstream symptoms such as diminished mucus clearance and recurrent infection. More recently, significant advances have been made in treating the cause of the disease by targeting the faulty gene responsible. Hope for the development of potential therapies lies with ongoing research into new pharmacological agents and gene therapy. This review gives an overview of $\mathrm{CF}$, and summarises the current evidence regarding the disease management and upcoming strategies aimed at treating or potentially curing this condition.
\end{abstract}

Key words: Cystic fibrosis; CFTR; treatment; infection; gene therapy.

Correspondence: Ryan Jaques, Molecular Physiology Laboratory, Centre for Atherothrombosis \& Metabolic Disease, Hull York Medical School, University of Hull

Cottingham Road, Hull HU6 7RX, UK. Tel. +44.1482.465008. E-mail: hyrj5@hyms.ac.uk

Contributions: RJ, concepted the design of the paper and wrote most of the main text. AS, wrote significant portions of the paper, specifically within the emerging molecular therapies section; he also revised and edited the final draft. $\mathrm{CH}$, provided additional information, revising, and helping draft the article. All contributors are satisfied with all aspects of the work.

Conflict of interest: $\mathrm{RJ}, \mathrm{AS}$ and $\mathrm{CH}$, have no competing interests, as we wrote this manuscript entirely by ourselves, and do not work for any corporation or government.

Funding: There was no funding for this manuscript. It was written and put together by RJ, AS and $\mathrm{CH}$.

Availability of data and materials: Data was only gathered from previously published clinical trials, as referenced in the paper. This data was mainly used in the tables to highlight the efficiencies of treatment. No data was taken by the authors as this is a review article.

Ethics approval and consent to participate: As this was a review article it does not require consent due to the absence of participants. 


\section{Introduction}

Cystic fibrosis (CF) is a life-long condition characterised primarily by a build-up of mucus in the lungs and digestive tracts [1]. The body's failure to remove this often leads to breathing difficulties and frequent lung infections [2]. Unfortunately, these manifestations become chronic as patients progress through life, with pulmonary disease and respiratory failure remaining the major cause of morbidity and mortality [3]. Currently, there is no cure for $\mathrm{CF}$, however with good management, patients often live well into adulthood with the average predicted survival standing at 48 years for males and 43 years for females [4]. Yet, the demanding routine patients must go through to control their symptoms often has deleterious effects on their physical and mental wellbeing. Ongoing research is trying to explore how we can minimise these problems, focusing on how best to manage, treat and possibly cure $\mathrm{CF}$.

The aim of this review is to critically discuss the current evidence on the therapeutic strategies for managing CF. Firstly, we provide an overview of $\mathrm{CF}$ in relation to its clinical presentation and pathophysiology and then look at the current options available for treatment. We will then explore future therapies, where emphasis may be given towards how we can target the underlying mechanisms of this genetic condition by focusing on pharmacological interventions that are currently undergoing investigation.

\section{Prevalence of $\mathrm{CF}$}

Various countries have introduced registers which track the number of patients diagnosed with CF [5-7]. These help to measure, appraise and compare aspects of cystic fibrosis, its diagnosis, and its treatment regimen, thereby encouraging new procedures to deal with this disease. Most countries within Africa, South America and parts of Asia have a limited or non-existent system due to health authorities prioritising other important public health issues; poverty, malnutrition, civil war, and outbreaks of infectious diseases are given greater emphasis [8]. For these reasons, the most accurate data concerning the prevalence of $\mathrm{CF}$ is usually found in countries within Europe and North America.

Each year, the European Cystic Fibrosis Society Patient Registry collects data on CF patients and causative mutations from Europe and neighbouring countries [5]. In the 2017 report [9], the number of CF patients registered totalled 48,204, though the amount is certain to be higher due to coverage varying from different countries [10]. In Romania for example, there is an estimated 35\% coverage in comparison to the UK which has a coverage of more than $95 \%$ [9]. Overall, the F508del mutation is the most frequent, with approximately $80 \%$ of patients detected as being F508del heterozygous and around $40 \%$ as being F508del homozygous. This is in comparison to the G542X allele mutation, the second most common, for which $2.69 \%$ of patients tested positive and N1303K with $2.19 \%$, although it should be noted that the geographical distributions of these variants can differ.

The frequency of CF in North America is similar to Europe, affecting 1 in 2,500-3,500 people [11,12]. However, there are differences in its distribution across the North American continent. This is primarily linked to ethnic group; the Caucasian population has a higher prevalence than other ethnicities, including Hispanics, Native Americans and those of African or Caribbean ancestry [8]. Consequently, as with Europe, North America's most prevalent mutation is the F508del mutation. The 2018 US Cystic Fibrosis Foundation Patients Registry report found that, in those genotyped, $84.7 \%$ of those in the registry had at least one F508del mutation, with $44.2 \%$ of those being homozygous for F508del [13]. There is a substantial drop in the next prevalent mutations which are G542X, $\mathrm{G} 551 \mathrm{D}$ and $\mathrm{R} 117 \mathrm{H}$. These are found to be at a prevalence of $4.6 \%$, $4.4 \%$ and $3.0 \%$ of the CF population, respectively. Due to its high frequency among Caucasian populations, it is the most common, potentially lethal inherited condition in this demographic [14].

\section{Pathophysiology}

Cystic fibrosis is an autosomal recessive disorder caused by a mutation on chromosome 7 at position q31.2 [15]. This location contains the cystic fibrosis transmembrane conductance regulator $(C F T R)$ gene which is $189 \mathrm{~kb}$ in length with 27 exons and 26 introns. The protein itself is made of 1,480 amino acids and consists of five domains. There are two transmembrane domains that are each connected to a nucleotide binding domain (NBD) in the cytoplasm. The first NBD is connected to the second transmembrane domain by a regulatory ' $R$ ' domain. For the channel to open, serine residues on the ' $R$ ' domain must be phosphorylated by a cAMP-dependent protein kinase and ATP must bind to both NBDs and be subsequently hydrolysed [16]. In its open state, the channel is responsible for the transport of anions, specifically bicarbonate and chloride ions, across the cell membrane [17]. Physiologically, chloride and bicarbonate ions are secreted onto the epithelial surface by the CFTR channel resulting in the secretion of fluid through osmosis. Any impairment in CFTR function may therefore lead to a decrease in CFTR-mediated chloride and bicarbonate secretion. Water resorption follows, creating a thick, viscous mucus which accumulates on the epithelial surfaces of bodily organs such as the lungs, liver, intestines and pancreas [18]. The CFTR channel is also involved in the regulation of the epithelial sodium channel $(\mathrm{ENaC})$, otherwise known as the amiloridesensitive sodium channel, found in the airways of the lungs [19].

While CF is a multi-organ disease, the dominant cause of morbidity and mortality is its effects on the lungs [20]. In the airways of the lungs, CFTR is highly expressed, where the buildup of mucus often causes breathing difficulties and increases the risk of infections. The airways are predominantly lined by pseudostratified columnar epithelium [21]. This epithelium is composed of numerous cell types including basal cells, club cells, ciliated cells, goblet cells, and pulmonary neuroendocrine cells (PNECs) amongst others. The pulmonary ionocytes are of particular importance to CF. These cells are derived from basal cells and are responsible for most of the CFTR expression in the airway epithelium. It is therefore thought that pulmonary ionocytes are heavily involved in fluid regulation and may play a critical role in the pathogenesis of CF [22].

Mucus build-up is primarily driven by dehydration of the airway surface liquid (ASL) that coats the epithelial cells of the airways. Hydration of the ASL is primarily regulated by CFTR-mediated anion secretion and ENaC-mediated sodium absorption. In $\mathrm{CF}$, an increase in $\mathrm{ENaC}$-mediated sodium absorption into the airway epithelial cells has been found alongside CFTR dysfunction, contributing to the dehydration of ASL [23]. This is thought to be due to the abolition of ENaC regulation by the CFTR channel, when CFTR is mutated and dysfunctional, as seen in CF [24]. The ASL is composed of a periciliary layer (PCL) that is covered with a mucus layer (ML) [25]. The ML is composed of mucins that form a gellike structure and are involved in trapping inhaled particles, while the PCL covers the cilia, preventing penetration by those inhaled particles. This allows the cilia to beat to remove inhaled particles through mucociliary clearance. Dehydration of the ASL leads to a decrease in PCL volume, resulting in the dehydrated ML compressing the cilia. This ultimately results in a decrease in the ability of the cilia to beat, thickened mucus, mucus stasis, and 
recurrent infections [26]. Over time this may progress into chronic lung disease and an overall decline in lung function.

CFTR is also strongly expressed in the sebaceous and eccrine sweat glands $[15,27]$. Defective CFTR results in reduced transport of sodium chloride in the absorptive duct and therefore results in saltier sweat. In the digestive tract, nutrition and vitamin deficiencies are common as mucus clogs the pancreas, preventing digestive enzymes from reaching the gut. Blockages of the small ducts in the liver and biliary system can lead to problems such as gallstones and liver disease, with the latter affecting roughly $30 \%$ of CF sufferers [28]. The reproductive systems are also not spared as the destruction of the vas deferens and epididymis are responsible for $95 \%$ of male CF patients being infertile [29]. In females, the majority are fertile but have thicker cervical mucus and may have ovulation issues due to poor nutrition.

There are 2,102 known mutations of the CFTR gene [30], over 1,850 of which are known to be disease-causing [31]. These are separated into classes I-VI as shown in Table 1. Patients with Class I-III mutations often have more severe clinical features due to either the absence of the CFTR protein at the cell surface, or the lack of efficient gating of the channel [32]. The most common mutation is the F508del mutation, which is a frameshift mutation caused by a deletion of phenylalanine at codon 508. As a class II mutation, it causes the misfolding of the CFTR protein, which is subsequently polyubiquitinated and destroyed by the cell proteasome [33]. Each mutation class confers a different defect in CFTR production and/or function, and therefore unique approaches are required when designing treatments that can target these alterations.

\section{Diagnosis of $\mathbf{C F}$}

There are several tests that can be utilised for diagnosing CF. Babies are screened for $\mathrm{CF}$ using the heel prick test and, as a result, most children are diagnosed shortly after birth. The test itself involves taking blood from the baby's heel at around 5 days of age, which is then sampled for several conditions including CF. The first stage of testing involves the measurement of Immunoreactive Trypsinogen (IRT) levels, which are raised in CF patients due to blockages of the pancreatic ducts [34]. If IRT is raised, mutation analysis of the CFTR gene is undertaken. To test positive, two copies of the faulty gene need to be identified, though further tests are required to confirm a diagnosis [35]. In this case, a sweat test will be ordered which measures the salt levels on the skin, as those with CF have higher chloride levels compared to the general population. The values of chloride and sodium in sweat are around $10-50 \mathrm{mmol} / \mathrm{L}$ in normal subjects, but in the patients with CF they are usually above $60 \mathrm{mmol} / \mathrm{L}$ and can be as high as $120 \mathrm{mmol} / \mathrm{L}$ [36].
Antenatal testing can be offered for potential parents who are aware they are both carriers. This may involve a chorionic biopsy or amniocentesis during pregnancy to identify the condition of the baby. Benefits of early diagnosis allow treatment to begin at birth, although these procedures can carry an increased risk of miscarriage.

New non-invasive techniques are available and can aid early diagnosis, although these are only accessible privately. The development of safer prenatal screening has been developed by the identification of circulating free foetal DNA in the maternal plasma in early gestation [37]. DNA reflecting both maternal and foetal material is collected from the maternal plasma, which is molecularly amplified by PCR and subsequently sequenced. The foetal DNA will be analysed to assess the inheritance of the CFTR mutation. Tests that can be offered include the paternal mutation exclusion when the parents carry different CF mutations, or where both parents are carriers of the same CF mutation. If the baby has inherited the paternal mutation, an invasive test may be required to see if the maternal mutation has also been inherited.

Cystic fibrosis can also be diagnosed later in life. This is because rarer mutations are not screened early on and may present with delayed symptoms that mimic other lung pathologies such as bronchitis, thus making an accurate diagnosis more challenging. Individuals may choose to get tested to determine if they carry a faulty CFTR gene, especially if they have a relative or history of $\mathrm{CF}$ in their family.

The nasal potential difference (NPD) test measures how well sodium and chloride flow across the mucous membrane lining the nasal cavity. NPD gives an in vivo measurement of CFTR function and sodium channel function in the respiratory epithelium [38]. This is helpful in distinguishing individuals with non-classic forms of CF with evidence of CFTR dysfunction, from individuals with normal CFTR function that are unlikely to have CF. This can therefore be used alongside sweat tests, especially in those with an intermediate sweat result and who may carry a rare or unknown mutation.

\section{Clinical assessment of disease progression}

Routine monitoring and assessments are crucial to assess any changes that can occur as patients progress through life. Comprehensive annual reviews are offered which include pulmonary, nutritional and psychological assessments [39]. Lung function is primarily singled-out as this has a significant impact on the patient's quality of life, especially if their lung disease has significantly advanced. To assess this, pulmonary testing is carried out through spirometry. This measures forced expiratory volume in 1 second $\left(\mathrm{FEV}_{1}\right)$, forced expiratory flow $(\mathrm{FEF})_{25-75 \%}$ and forced vital

Table 1. CFTR mutation classes and required strategies for treating cystic fibrosis.

\begin{tabular}{|c|c|c|c|c|}
\hline Classification & CFTR defect & Mutation examples & Required approaches & Drug required (Approved?) \\
\hline Class I & No functional CFTR protein/mRNA & G542X, W1282X, R553X & Salvage protein synthesis & Bypass therapy (no), Read through agents (no) \\
\hline Class II & CFTR trafficking defect & $\Delta \mathrm{F} 508, \Delta 507, \mathrm{~N} 1303 \mathrm{~K}$ & Correct protein folding & Corrector (yes) \\
\hline Class III & Impaired gating & G551D, V520F, S549N & Recover channel conductance & Potentiator (yes) \\
\hline Class IV & Decreased channel conductance & R334W, R117H, S1235R & Recover channel conductance & Potentiator (only for R117H) \\
\hline Class V & Reduced production of CFTR & A455E, $1680-886 \mathrm{~A} \rightarrow \mathrm{G}$ & Improve maturation/correct splicing & $\begin{array}{l}\text { Antisense oligonucleotides (no), Corrector (no), } \\
\text { Amplifier (no) }\end{array}$ \\
\hline Class VI & Decreased CFTR stability & Q1412X, 4279 insA & Promote protein stability & Stabilisers (no) \\
\hline
\end{tabular}


capacity (FVC), with oxygen saturation measured to further determine lung condition. Weight and height are used as key indicators in evaluating growth and nutritional status. These go alongside tests that look for CF-related disorders such as diabetes and liver disease [40]. Sputum samples are also taken for microbiological analysis or, if this is not possible, cough swabs or nasopharyngeal aspirates can be used. Any significant abnormalities found in any of these tests may call for clinicians to alter treatment.

Alongside this, regular routine reviews are carried out. These are more frequent in earlier life and start immediately after diagnosis. In the first month of life these reviews occur weekly, progressing to monthly during the first year, and then incrementing to every 3 to 6 months as patients progress into adulthood. These reviews look at treatment adherence, quality of life and any complications or concerns patients may have [41]. Sudden onset of pulmonary exacerbations can regularly appear, and they are normally caused by an acute pulmonary infection. These often need to be clinically managed, and so chest X-rays may be beneficial in looking for radiological abnormalities.

\section{Non-pharmacological management}

Patients can implement several techniques that may help to improve their symptoms. Physiotherapy is performed daily, which helps to clear the airways and loosens mucus in the lungs. It can also be adapted to individual needs, as certain techniques can improve problems such as urinary incontinence and inhaled medication compliance $[42,43]$. Frequent exercise is strongly advised as this can loosen up sputum, increase respiratory muscle endurance and reduce lung residual volume $[44,45]$.

It is highly important for patients to maintain good nutrition, as a healthy body weight has been directly linked to better lung function and fewer chest infections [46]. Unfortunately, due to the GI tract being congested, malabsorption is a common problem especially in early life $[15,47]$. To help manage this, more calories need to be consumed and digestive enzyme replacements are given to help aid the breakdown of food [48]. Even with supplementation, CF can increase the body's energy requirements by over $100 \%$ which is challenging for many, particularly for those with poor appetite [49]. Performing these tasks can be a burden, which partially explains why psychological distress is frequently seen among sufferers. Recent studies highlight the vast increase in symptoms of depression and anxiety in both individuals with CF and their caregivers [50,51]. Prevalence data shows that these problems are 2-3 times more prevalent than in the general background population [52-54]. To combat this, countries such as the UK have introduced guidelines where annual reviews assess wellbeing, quality of life and treatment adherence [55].

\section{Established drug therapies}

Until recently, patients have relied on therapies that treat the symptoms rather than the underlying cause. Such options have included the inhalation of mucoactive agents such as hypertonic saline, rhDNase and mannitol powder. These aim to help thin the mucus on the lung epithelium, making it easier to cough out.

Hypertonic saline works by increasing the amount of salt in the airways, which attracts water and thins the mucus [56]. It is available in different concentrations of $3 \%, 3.5 \%$ and $7 \%$. People who are 6 years or older or those with $\mathrm{FEV}_{1}$ greater than $40 \%$ percent predicted can be offered this. Although the guidelines do not advocate for its use among those younger than 6 , a recent study has shown that inhaled hypertonic saline improved lung clearance in children aged 3-6 years and could be a suitable early intervention [57].

rhDNase (Dornase alfa; Pulmozyme ${ }^{\circledR}$ ) is approved for people 5 years and older. It works as an enzyme which hydrolyzes the DNA in the mucus and reduces sputum viscoelasticity [58]. Comparisons to hypertonic saline show superiority in improving lung function in several trials, with one indicating that rhDNase given on alternative days rather than daily is equally effective [59-61]. Mannitol powder has also been recommended as an option, although stricter criteria have been put on its usage. The criteria are as follows: inadequate response to rhDNase, declining lung function $\left(>2 \%\right.$ decline in $\mathrm{FEV}_{1}$ annually), and where other osmotic agents are not appropriate. The exact mechanism of action is unknown, though it is thought to change the viscoelastic properties of mucus. It does this by rehydrating the PCL, thereby increasing clearance through mucociliary activity [62].

Bronchodilators can be used alongside mucolytics as these widen the airways, allowing mucus to move easily from smaller airways to larger ones. These also help with bronchospasms which are a common side effect of inhaled treatments [63].

\section{Molecular therapies for $\mathbf{C F}$}

Recently, a number of new drugs have been made available which have shown favourable results in several Phase III clinical trials [64-79], as shown in Table 2. These have been designed to target the underlying mechanism responsible for creating the ineffective CFTR protein.

The first therapeutic drug that has demonstrated significant clinical effects is Ivacaftor $\left(\right.$ Kalydeco $\left.^{\circledR}\right)$. Developed by Vertex Pharmaceuticals, it is the first of its kind to target the underlying gene defect. It works by modulating inefficient CFTR channels at the cell surface causing them to open [80]. The main target is the G551D mutation, a Class III defect and the most prevalent gating mutation [81]. Several completed studies highlight the significant improvements in percent predicted forced expiratory volume in one second $\left(\mathrm{ppFEV}_{1}\right)$ and other clinical outcomes in class III and IV mutations [64-68]. The main drawback of Ivacaftor is that there is no supportive evidence that it is effective for those with a F508del mutation, which accounts for the majority of cases in Europe and North America $[4,10,13]$. This Class II mutation causes ineffective protein folding. To target this, Vertex has designed Lumacaftor which acts as a chaperone during protein folding, increasing the number of efficient CFTR proteins at the cell surface [82]. Evidence shows that as a monotherapy, it is ineffective at providing significant improvements in lung function, but may have potential for use in combination with other drugs [83]. To fully combat the F508del mutation, Vertex has created co-formulated combinations aimed at maximising the number of effective CFTR channels. The first of these is Ivacaftor/Lumacaftor (Orkambi $\left.{ }^{\circledR}\right)$, which utilises the dual action of both drugs by helping the protein fold correctly and then modulating the channel after it has reached the cell membrane. Some Phase III studies involving Orkambi ${ }^{\circledR}$ have demonstrated significant improvements in ppFEV $_{1}$ [72-74], although others have not identified such significance [69-71]. Another combination treatment is Tezacaftor/Ivacaftor (Symdeko ${ }^{\circledR}$ in US, Symkevi ${ }^{\circledR}$ in EU). Tezacaftor has been designed to facilitate the processing and trafficking of the CTFR protein towards the cell surface. In the two biggest completed Phase III studies, EVOLVE and EXPAND, the Tezacaftor/Ivacaftor group showed significant improvements in ppFEV $_{1}$ [76-77], although a smaller study showed no significant increase in $\mathrm{ppFEV}_{1}[75]$.

Vertex has recently produced a triple combination therapy consisting of a combination of Elexacaftor/Tezacaftor/Ivacaftor 
(Trikafta ${ }^{\circledR}$ in US, Kaftrio ${ }^{\circledR}$ in EU) that is used in a combination regimen with ivacaftor. Elexacaftor, like Tezacaftor, is a CFTR corrector but binds to a different site and facilitates the cellular processing and trafficking of the CFTR protein to the cell surface [84]. Of the two completed Phase III clinical trials shown in Table 2 , greater improvements have been shown in the average $\mathrm{ppEV}_{1}$ and CFT-R score than either Orkambi ${ }^{\circledR}$ or Symkevi ${ }^{\circledR}$ [78-79]. Significant reductions in sweat chloride concentration have also been shown compared to trials involving the other dual therapies.

Although these molecular therapies have shown great benefit, there are several side effects that need to be considered before starting treatment. Common side effects associated with these drug therapies include headaches, upper respiratory tract infections, nasal congestion, abdominal pain, nasopharyngitis, diarrhoea, rash, nausea, and dizziness [64-79]. One of the more severe side effects is the worsening of liver function, as these treatments have been shown to increase blood liver enzyme levels [85,86]. This is indicative of hepatic impairment. Blood tests assessing liver function must be undertaken before initiation, then every 3 months during the first year, followed by annual appointments. These therapies have also been shown to increase the risk of cataracts in some children and adolescents [87-90], so an eye examination should be performed before and during treatment. The therapeutic effectiveness of these therapies can vary if in concomitant use with

Table 2. Published phase III clinical trials for new drug therapies for cystic fibrosis (up to June 2020).

\begin{tabular}{|c|c|c|c|c|c|c|c|}
\hline Drug & Study Name & Outcome(s) & Age & Length & Mutation & Main finding in treatment group & $\operatorname{Re}$ \\
\hline \multirow[t]{5}{*}{$\begin{array}{l}\text { Ivacaftor } \\
\text { (Kalydeco®) }\end{array}$} & $\begin{array}{l}\text { KONDUCT } \\
(\mathrm{n}=69)\end{array}$ & $\begin{array}{l}\text { I. Safety } \\
\text { II. Change in ppFEV }\end{array}$ & $\geq 6$ Yrs & $24 \mathrm{~W}$ & R117H & $\begin{array}{l}\text { Mean absolute } \mathrm{ppFV}_{1} \text { significantly } \\
\text { increased for those }>18 \text { years by } 5.0 \% \\
(95 \% \mathrm{CI} 1.15-8.78 \%) \text {, not in those aged } 6-11 \text { years. }\end{array}$ & 64 \\
\hline & $\begin{array}{l}\text { KONNECTION } \\
(\mathrm{n}=39)\end{array}$ & I. Change in ppFEV & $\geq 6$ Yrs & $24 \mathrm{~W}$ & Non-G551D Gating & $\begin{array}{l}\text { Significant improvement in BMI and sweat chloride. } \mathrm{ppFV}_{1} \\
\text { with model-adjusted absolute mean increased by } 10.7 \% \\
(95 \% \text { CI } 7.3-14.1 \%) \text { at } 8 \mathrm{~W} \text { and was maintained through } 24 \mathrm{~W} \text {. }\end{array}$ & 65 \\
\hline & $\begin{array}{l}\text { ENVISION } \\
(\mathrm{n}=52)\end{array}$ & I. Change in ppFEV & $6-11$ Yrs & $48 \mathrm{~W}$ & G551D & $\begin{array}{l}\text { Significant increase in adjusted ppFEV } \text { when compared } \\
\text { to placebo }(10.7 \% \text { vs. } 0.7 \%, P<0.001) \text {. Mean gain of } 2.8 \mathrm{~kg} \\
\text { more than placebo with sweat chloride levels significantly reduced. }\end{array}$ & 66 \\
\hline & $\begin{array}{l}\text { PERSIST } \\
(\mathrm{n}=192)\end{array}$ & $\begin{array}{l}\text { I. AE's } \\
\text { II. Change in } \mathrm{ppFEV}_{1}\end{array}$ & $\geq 6$ Yrs & $144 \mathrm{~W}$ & G551D & $\begin{array}{l}\text { Well tolerated. Sustained improvements in ppFEV } \\
\text { and weight in all ages. PEx remained suppressed in adult/ }\end{array}$ & 67 \\
\hline & $\begin{array}{l}\text { STRIVE } \\
(\mathrm{n}=161)\end{array}$ & I. Change in ppFEV ${ }_{1}$ & $\geq 12$ Yrs & $48 \mathrm{~W}$ & G551D & $\begin{array}{l}\text { Significant increase in } \mathrm{ppFEV}_{1} \text { at } 24 \mathrm{~W}(10.6 \%) \text { and maintained } \\
\text { at W48. PEx reduced by } 55 \% \text { and sweat chloride was } \\
\text { significantly reduced. Mean gain of } 2.7 \mathrm{~kg} \text { compared to placebo. }\end{array}$ & 68 \\
\hline \multirow{6}{*}{$\begin{array}{l}\text { Lumacaftor/ } \\
\text { Ivacaftor } \\
\text { (Orkambi®) }\end{array}$} & $\begin{array}{l}\text { VX15-809-115 } \\
(\mathrm{n}=60)\end{array}$ & $\begin{array}{l}\text { I. AE } \\
\text { II. Sweat chloride }\end{array}$ & $2-5$ Yrs & $24 \mathrm{~W}$ & 2 F508del & $\begin{array}{l}\text { Both drugs well tolerated. Mean sweat chloride } \\
\text { concentrations decreased on average } 31.7 \mathrm{mmo} / \mathrm{L} \text {. }\end{array}$ & 69 \\
\hline & $\begin{array}{l}\text { VX13-809-011 } \\
(\mathrm{n}=58)\end{array}$ & $\begin{array}{l}\text { I. } A E \\
\text { II. Change in ppFEV }\end{array}$ & $6-11$ Yrs & $24 \mathrm{~W}$ & 2 F508del & $\begin{array}{l}\text { Well tolerated. No significant change in ppFEVl, but significant } \\
\text { improvements in BMI, CFQ-R scores and sweat chloride level } \\
\text { reduced by } 24.8 \mathrm{mmo} / \mathrm{L} \text {. }\end{array}$ & 70 \\
\hline & $\begin{array}{l}\text { VX14-809-106 } \\
(\mathrm{n}=46)\end{array}$ & $\begin{array}{l}\text { I. AE } \\
\text { II. Change in } \mathrm{ppFEV}_{1}\end{array}$ & $\geq 12$ Yrs & $24 \mathrm{~W}$ & 2 F508del & $\begin{array}{l}\text { Severe lung disease patients receiving half dose had less } \\
\text { respiratory events with shorter duration. ppFEV }{ }_{1} \text { was similar } \\
\text { to baseline from } 4 \mathrm{~W} \text { onward. }\end{array}$ & 71 \\
\hline & $\begin{array}{l}\text { TRAFFIC and } \\
\text { TRANSPORT } \\
(\mathrm{n}=1108)\end{array}$ & I. Change in ppFEV ${ }_{1}$ & $\geq 12$ Yrs & $24 \mathrm{~W}$ & 2 F508del & $\begin{array}{l}\text { Significant improvements in } \mathrm{ppFV}_{1} \text { in those with varying degrees } \\
\text { of lung function. Significant improvements in BMI and PEx. } \\
\text { Some AEs were higher in intervention groups. }\end{array}$ & 72 \\
\hline & $\begin{array}{l}\text { VX14-809-109 } \\
(\mathrm{n}=206)\end{array}$ & $\begin{array}{l}\text { I. Lung clearance } \\
\text { II. Change in ppFEV }\end{array}$ & 6-11 Yrs & $24 \mathrm{~W}$ & 2 F508del & $\begin{array}{l}\text { Significant improvement in lung function; change in LCI2.5 by }-1.09 \\
\text { units ( } 95 \% \text { CI }-1.43 \text { to }-0.75) \text { and absolute change ppFEV by } 2.4 \% \\
(95 \% \text { CI 0.4-4.4\%) using least square mean analysis. }\end{array}$ & 73 \\
\hline & $\begin{array}{l}\text { PROGRESS } \\
(\mathrm{N}=1030)\end{array}$ & $\begin{array}{l}\text { I. AE } \\
\text { II. Change in ppFEV }\end{array}$ & $\geq 12$ Yrs & $96 \mathrm{~W}$ & 2 F508del & $\begin{array}{l}\mathrm{ppFEV} V_{1} \text { was maintained from continued treatment. PEx rate } \\
\text { remained lower than placebo. Annual ppFEV } 1 \text { decline was reduced. }\end{array}$ & 74 \\
\hline \multirow{3}{*}{$\begin{array}{l}\text { Tezacaftor/ } \\
\text { Ivacaftor } \\
\text { (Symdeko }^{\circledR} \text { in US, } \\
\text { Symkevi® }{ }^{\circledR} \text { in EU }\end{array}$} & $\begin{array}{l}\text { VX15-661-113 } \\
(\mathrm{n}=70)\end{array}$ & $\begin{array}{l}\text { I. Safety } \\
\text { II. Change in } p p F E V_{1}\end{array}$ & 6-11 Yrs & $24 \mathrm{~W}$ & $\geq 1 \mathrm{~F} 508 \mathrm{del}+1 \mathrm{~F} / \mathrm{RF}$ & $\begin{array}{l}\text { Well tolerated. Significantly improved sweat chloride levels } \\
\text { and CFQ-R scores. Mean absolute change ppFEV remained stable. }\end{array}$ & 75 \\
\hline & $\begin{array}{l}\text { EVOLVE } \\
(\mathrm{n}=510)\end{array}$ & $\begin{array}{l}\text { I. Change in ppFEV } \\
\text { II. PEx }\end{array}$ & $\geq 12$ Yrs & $24 \mathrm{~W}$ & 2 F508del & $\begin{array}{l}\text { PEx were } 35 \% \text { lower. Absolute and relative mean changes in } \mathrm{pPFV}_{1} \\
\text { significantly improved by } 4.0 \% \text { ( } 95 \% \text { CI } 3.1-4.8 \% \text { ) and } 6.8 \% \\
\text { (95\% CI 5.3-8.3) respectively ( } \mathrm{P}<0.001 \text { for both). }\end{array}$ & 76 \\
\hline & $\begin{array}{l}\text { EXPAND } \\
(\mathrm{n}=248)\end{array}$ & I. Change in ppFEV & $\geq 12$ Yrs & $24 \mathrm{~W}$ & 1 F508del + 1 F/RF & $\begin{array}{l}\text { Absolute change ppFEV }{ }_{1} \text { was significantly increased in } \\
\text { Tezacaftor/lvacaftor group by } 6.8 \% \text { ( } 95 \% \text { CI } 5.7-7.8 \%) \text { and Ivacaftor } \\
\text { group by } 4.7 \% \text { ( } 95 \% \text { CI, 3.7-5.8\%) compared to placebo. }\end{array}$ & 77 \\
\hline \multirow{2}{*}{$\begin{array}{l}\text { Elexacaftor/ } \\
\text { Tezacaftor/lvacaftor } \\
\text { (Trikafta }^{\circledR} \\
\text { in US/Kaftrio } \\
\text { in EU) }\end{array}$} & $\begin{array}{l}\text { VX17-445-102 } \\
(\mathrm{n}=403)\end{array}$ & I. Change in ppFEV & $\geq 12$ Yrs & $24 \mathrm{Wl}$ & F508del + 1 F/MF & $\begin{array}{l}\mathrm{ppFEV}_{1} \text { was significantly higher at } 4 \mathrm{~W}(13.8 \%) \text { and } 24 \mathrm{~W}(14.3 \%) \\
\text { checkpoints. PExs were } 63 \% \text { lower with sweat chloride } \\
\text { levels significant reduced. }\end{array}$ & 78 \\
\hline & $\begin{array}{l}\text { VX17-445-103 } \\
(\mathrm{n}=113)\end{array}$ & $\begin{array}{l}\text { I. Change in ppFEV } 1 \\
\text { II. Sweat Chloride }\end{array}$ & $\geq 12$ Yrs & $4 \mathrm{~W}$ & 2 F508del & $\begin{array}{l}\text { Elexacaftor/Tezacaftor/lvacaftor group had significant } \\
\text { increase in ppFEV } 1 \text { of } 10.0 \%(95 \% \mathrm{CI} 7 \cdot 4-12 \cdot 6 \%) \text { and significant } \\
\text { improvement in sweat chloride levels by } 45 \cdot 1 \mathrm{mmol} / \mathrm{L} \\
(95 \% \mathrm{CI}-50 \cdot 1 \text { to }-40 \cdot 1) \text { compared to Tezacaftor/lvacaftor group. }\end{array}$ & 79 \\
\hline
\end{tabular}

Ref., Reference; $n$, number of enrolled participants; $\mathrm{ppFEV}_{1}$, percent predicted forced expiratory volume in one second; CI, confidence intervals; Yrs, years; W, weeks; BMI, body mass index; $\mathrm{AE}$, adverse effects; PEx, pulmonary exacerbations; CFQ-R, cystic fibrosis questionnaire-revised; LCI, lung clearance index; RCT, randomised control trial; F/RF, residual function mutation; F/MF, minimal function mutation. 
other medications that induce or inhibit CYP3A4 enzymes. Therefore, a drug history and review would have to be undertaken before starting any treatment.

The therapeutic indications for these new molecular therapies are shown in Table 3. These include the authorised use from the US Food and Drug administration, and European Medicines Agency. Currently in the EU, Kalydeco's approval covers the medication's use in children as young as six months, while the approval for Symkevi ${ }^{\circledR}$ allows its use in patients aged 12 or older. This may soon be reduced to 4 months for Kalydeco ${ }^{\circledR}$ and 6 years for Symkevi ${ }^{\circledR}$ as this has been recommended to be green lighted by the European Medicines Agency [91,92].

\section{Use of bronchodilators}

Bronchodilators are primarily used in the treatment of chronic obstructive diseases, but their role in CF is less clear. Measurements of $\mathrm{FEV}_{1}$ and FVC amongst CF patients can change up to $20 \%$ throughout the day, so assessing the effects bronchodilators is difficult [93]. The mechanism by which CF causes airway inflammation differs from asthma, resulting in a progressive nonreversible airflow obstruction [94]. In some cases, asthma can occur alongside CF, but obtaining a diagnosis is difficult due the similarity of symptoms these conditions present with. Furthermore, there is no universal definition of asthma which makes it harder to confirm a concomitant diagnosis. According to the European Epidemiologic Registry of Cystic Fibrosis and the North American Epidemiologic Study of Cystic Fibrosis databases, the prevalence of asthma in CF patients is around $17 \%$ and $19 \%$ respectively, with identical proportions seen amongst children and adults [95]. It could be assumed this would translate into the CF population; however, this assumption cannot be made as there are ongoing discussions over whether CF gene heterozygosity predisposes asthma development [96,97].

Only a limited number of trials show short acting beta- ${ }_{2}$ agonists increasing $\mathrm{ppFEV}_{1}$ in the short term, with increases in peak expiratory flow rate mostly seen in the long term in those with bronchial hyperreactivity and/or bronchodilator responsiveness [98]. Contrary to this, there have been other trials that have shown no clinical benefit. To further evaluate the use of this therapy, an investigation is underway examining the effects of a short acting beta- $_{2}$ agonist (Salbutamol) on shortness of breath, exercise performance and breathing responses in adults with $\mathrm{CF}$ (NCT03522831).

A recent Cochrane review into the use of long-term bronchodilators suggests that neither beta- ${ }_{2}$ agonists nor muscarinic antagonists produce significant improvements in $\mathrm{ppFEV}_{1}$, adverse events or quality of life [99]. The only suggested benefit was that it may help reduce the burden for CF patients as they can be taken less frequently. These conclusions have led some experts to recommend that these drugs should not be prescribed [100].

One area of similarity between CF and asthma is the involvement of the small airways (airways $<2 \mathrm{~mm}$ ). In both CF and asthma, the small airways are thickened due to inflammation, and are now thought to a play a central role in CF lung disease [101]. The small airways have traditionally been referred to as the "silent zone" of the lungs due to their relatively small contribution to total respiratory resistance. As a consequence, any damage to the small airways may not result in symptoms until the damage is advanced [102]. Recent evidence suggests that this "silent zone" may play a much greater role in airway pathology than previously thought and possibly could be used as a prognostic indicator [103]. Due to the central role of the small airways in CF lung pathology, they may serve as a target for future therapies. This could be particularly important for patients who suffer with asthma alongside CF.

\section{Inhaled corticosteroids}

The use of inhaled corticosteroids (ICS) as anti-inflammatory agents in both adults and children with CF is not often

Table 3. Authorised use of new drug therapies in the EU and US.

\section{Drug (trade name) EMA therapeutic indication}

Ivacaftor $\left(\right.$ Kalydeco $\left.^{\circledR}\right) \quad$ Kalydeco® is used on its own to treat cystic

fibrosis in patients aged 6 months and above

who have one of the following mutations in the

CFTR gene: R117H, G551D, G1244E, G1349D, G178R, G551S, S1251N, S1255P, S549N and S549R.

\begin{tabular}{|c|c|}
\hline 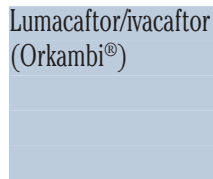 & $\begin{array}{l}\text { Orkambi® tablets are indicated for the treatment of CF } \\
\text { in patients aged } 2 \text { years and older who are homozygous for the } \\
\text { F508del mutation in the CFTR gene. Orkambi® granules are } \\
\text { indicated for the treatment of CF in children aged } 2 \text { years and } \\
\text { older who are homozygous for the F508del mutation in the CFTR gene. }\end{array}$ \\
\hline $\begin{array}{l}\text { Tezacaftor/lvacaftor } \\
\text { (Symdeko }{ }^{\circledR} \text { in US, } \\
\text { Symkevi }^{\circledR} \text { in EU) }\end{array}$ & $\begin{array}{l}\text { Symkevi@ is indicated in a combination regimen with ivacaftor for the } \\
\text { treatment of patients with CF aged } 12 \text { years and older who are } \\
\text { homozygous for the F508del mutation or who are heterozygous } \\
\text { for the F508del mutation and have one of the following mutations } \\
\text { in the CFTR gene: P67L, R117C, L206W, R352Q, A455E, D579G, 711+ } \\
3 \mathrm{~A} \rightarrow \mathrm{G} \text {, S945L, S977F, R1070W, D1152H, 2789+5G } \rightarrow \text { A, 3272 26A } \rightarrow \text { G, } \\
\text { and 3849+10kbC } \rightarrow \text { T. }\end{array}$ \\
\hline
\end{tabular}

Elexacaftor/Tezacaftor/ Kaftrio $®$ is indicated in a combination regimen with ivacaftor for the Ivacaftor (Trikafta ${ }^{\circledR}$ in US/Kaftrio ${ }^{\circledR}$ in EU)
Kaftrio $®$ is indicated in a combination regimen with ivacaftor
treatment of $C F$ in patients aged 12 years and older who are homozygous for the F508del mutation in the CFTR gene or heterozygous for F508del in the CFTR gene with a minimal function mutation.

\section{US FDA therapeutic indication}

Kalydeco® is used on its own to treat cystic fibrosis in patients aged 4 months and over who have one of 10 mutations in the CFTR gene: G551D, G178R, S549N, S549R, G551S, G1244E, S1251N, S1255P, G1349D or R117H.

Orkambi $®$ tablets are indicated for the treatment of $\mathrm{CF}$ in patients aged 2 years and older who are homozygous for the F508del mutation in the CFTR gene. Orkambi® granules are indicated for the treatment of cystic fibrosis $\mathrm{CF}$ in children aged 2 years and older who are homozygous for the F508del mutation in the CFTR gene.

Symdeko ${ }^{\circledR}$ is indicated in a combination regimen with ivacaftor for the treatment of patients with $\mathrm{CF}$ aged 6 years and older who are homozygous for the F508del mutation or have a single copy of the following mutations in the CFTR gene: A455E, E56K, R74W, A1067T, E193K, R117C, D110E, F1052V, R347H, D110H, F1074L, R352Q, D579G, K1060T, R1070W, D1152H, L206W, S945L, D1270N, P67L, S977F, 711+3A $\rightarrow$ G, 3272-26A $\rightarrow$ G, $\mathrm{E} 831 \mathrm{X}, 2789+5 \mathrm{G} \rightarrow \mathrm{A}, 3849+10 \mathrm{kbC} \rightarrow \mathrm{T}$.

Trikafta ${ }^{\circledR}$ is indicated in a combination regimen with ivacaftor for the treatment of $\mathrm{CF}$ in patients aged 12 years and older who have at least one F508del mutation in the CFTR gene. 
recommended. There is no evidence to suggest that these improve lung function or quality of life [104]. In fact, there is some evidence to suggest there is an adverse effect on growth at high dosages [105]. Therefore, the use of corticosteroids should be restricted to those with symptomatic wheezing if deemed to be beneficial. Regular assessments will be needed to identify if the treatment is working, as well as to identify any side effects. However, it is important to consider that corticosteroids are heterogeneous, resulting in different side-effect profiles. An example of this is the increased risk of pneumonia in patients taking fluticasone, alone or in combination with salmeterol, whilst there is no similarly reported increased risk of pneumonia in patients taking a budesonide/formoterol combination. The use of some steroids can therefore be safer than others and careful attention must be paid to the side effect profiles of individual ICS [106].

\section{Lung transplantation}

Due to the absence of a cure, there may be a point where conventional treatments no longer work. In this scenario, medical staff may then have to decide whether a lung transplant is the most viable option. Other organs such as the liver or pancreas are also examined for possible transplantation, but only if necessary. There is no way to determine how long a patient will have to wait for a transplant. This would depend upon how the transplant team have evaluated their condition, but also on the availability of a donor that is a good match for the patient. For most, this takes several months where only two in three will be successful in having a transplant [107]. Survival rates at 5 years after the procedure are approximately $60 \%$ among CF patients, with many of these living for at least 10 years [108].

\section{Antibiotic treatment and prophylaxis}

As well as airway obstruction, $\mathrm{CF}$ is characterised by chronic bacterial infections and inflammatory exacerbations [15,109]. It is not known whether the predisposition to infection is caused by decreased ASL alone, or whether environmental factors or even immunological defects are at play. What becomes clear however, is that CF lung pathogenesis begins with the altered lung environment triggered by the abnormal CFTR.

The microbiome of the lung environment in $\mathrm{CF}$ is different from that of healthy people, as the diversity changes as patients get older and their lung disease progresses [110]. The traditional view proposes that bacterial communities become less diverse with antibiotic usage and advancing lung disease [111]. The community thereby becomes dominated with bacteria such as Staphylococcus aureus (S. aureus) or opportunistic pathogens such as Pseudomonas aeruginosa (P. aeruginosa), Haemophilus influenzae (H. influenzae), Stenotrophomonas maltophilia (S. maltophilia), Burkholderia cepacian (B. cepacian), and Achromobacter xylosoxidans ( $A$. xylosoxidans), with $P$. aeruginosa being the predominate lung infection in CF [112]. All of these, with the exception of $S$. aureus, are gram negative and are associated with steep declines in lung function, increased risk of exacerbations and greater risk of mortality [113].

Recognition of the diverse microbiota raises questions on how best to approach antibiotic treatment. In terms of antibiotic resistance, $S$. maltophilia, $B$. cepacia and $P$. aeruginosa have been found to be difficult to kill due to their vast array of resistance mechanisms [114]. These include Beta-lactamases, efflux pumps, and biofilm formation which increase their resistance to aminoglycosides, flouroquinolones and Beta-lactams [115]. In some cases, especially in early life, antibiotic prophylaxis may be given to prevent infection and lung damage. Any changes to the treatment regimen will have to be evaluated beforehand. This will look at the potential side effects that may arise, such as the possibility of drug toxicity when using drugs such as Streptomycin, Kanamycin and Amikacin to treat non-tuberculous mycobacteria. These drugs can have adverse effects on auditory, vestibular, renal and neuromuscular function [116]. These also have been shown to interfere with CY3PA4 enzymes, and therefore patients being treated with the new molecular therapies (Kalydeco ${ }$, Orkambi ${ }^{\circledR}$, Symkevi ${ }^{\circledR} /$ Symdeko ${ }^{\circledR}$, or Trikafta ${ }^{\circledR} /$ Kaftrio $\left.{ }^{\circledR}\right)$ need to be closely monitored.

\section{Ongoing clinical trials}

In the first part of this review we have discussed the current management of CF. Next, we will expand into novel treatment possibilities, exploring how these could improve upon treating the underlying mechanism of CF. Many clinical trials are currently underway, which look at treatments that aim to improve pulmonary function, as shown in Table 4. This does not include trials aiming to treat pulmonary exacerbations or lung infections, but the compounds may reduce the number of these as a secondary effect.

\section{Emerging molecular therapies}

There is ongoing development on a variety of new potentiators and correctors. Alongside this, entirely new classes of CFTR modulators are in development, primarily read-through agents and CFTR amplifiers. Potentiators and correctors currently in development are shown in Table 4. ABBV-3067 (formerly known as GLPG-3067) has completed Phase I clinical trials (NCT03128606) and preliminary results seem to indicate that the drug was well tolerated [117]. As shown in Table 4, it is now in Phase II clinical trials alone and in combination with ABBV-2222 (formerly known as GLPG-2222), a corrector that demonstrated advantages over the first generation correctors Lumacaftor and Tezacaftor in preclinical studies [118]. The new CFTR modulators PTI-801, PTI-808 and PTI-428 are being tested in combination, as seen in Table 4. PTI- 801 is a corrector, PTI- 808 is a potentiator, and PTI-428 is a novel class of CFTR modulator known as an "amplifier". This triple combination has completed Phase II trials in patients with at least one copy of the F508del mutation (NCT03251092), with a reported significant improvement in ppFEV1 and reduction in sweat chloride concentration [119].There are now plans to move ahead with two Phase III clinical trials; the MORE (Modulator Options to RestorE CFTR) trial for subjects that are homozygous for F508del to confirm the efficacy of the triple combination and the CHOICES (Crossover trial based on Human Organoid Individual response in $\mathrm{CF}$ ) trial that aims to develop the area of personalised medicine in CF [120].

\section{CFTR amplifiers}

Of particular significance is the amplifier PTI-428. Amplifier agents work to increase the levels of CFTR protein by stabilising CFTR mRNA. The very early experimental compound known as PTI-CH acted in a mutation-agnostic fashion and demonstrated efficacy in preclinical studies [121]. The development of PTI-428, a first-in-class amplifier, followed. In a Phase II study assessing the safety and efficacy of PTI-428 in patients taking Orkambi ${ }^{\circledR}$, the test group exhibited a $5.2 \%$ increase in mean absolute improvement in 
Table 4. Current active and/or recruiting studies for drug therapies for cystic fibrosis (up to June 2020).

\begin{tabular}{|c|c|c|c|c|c|c|c|}
\hline $\begin{array}{l}\text { Intervention } \\
\text { drug(s) }\end{array}$ & Age & Phase & Drug action & Allele mutation & $\begin{array}{l}\text { Trial no. } \\
\text { criteria }\end{array}$ & Status & Sponsor \\
\hline ELXX-02 & $\geq 18$ years & II & ERSG & $\geq 1 \mathrm{G} 542 \mathrm{X}$ & NCT04126473 & Recruiting & $\begin{array}{l}\text { Eloxx } \\
\text { Pharmaceuticals }\end{array}$ \\
\hline Orkambiß & $\geq 12$ years & - & Potentiator/corrector & 2 F508del & NCT03894657 & Recruiting & $\begin{array}{l}\text { Assistance Publique } \\
\text { - Hôpitaux de Paris }\end{array}$ \\
\hline TEZ/IVA & $\geq 6$ years & III & Potentiator/corrector & $\geq 1$ F508del & NCT03537651 & Active, not recruiting & $\begin{array}{l}\text { Vertex } \\
\text { Pharmaceuticals }\end{array}$ \\
\hline ELX/TEZ/IVA & $\geq 12$ years & III & Potentiator/corrector & $\geq 1$ F508del + 1 (F/MF) & NCT03447262 & Active, not recruiting & $\begin{array}{l}\text { Vertex } \\
\text { Pharmaceuticals }\end{array}$ \\
\hline ELX/EZ/IVA & $\geq 12$ years & III & Potentiator/corrector & 1 F508del + 1 (F/G and F/RF) & NCT04058366 & Enrolling by invitation & $\begin{array}{l}\text { Vertex } \\
\text { Pharmaceuticals }\end{array}$ \\
\hline ELX/IEZ/IVA & $\geq 12$ years & III & Potentiator/corrector & 1 F508del + 1 (F/G and F/RF) & NCT04058353 & Recruiting & $\begin{array}{l}\text { Vertex } \\
\text { Pharmaceuticals }\end{array}$ \\
\hline ELX/EZ/IVA & $\geq 12$ years & III & Potentiator/corrector & $\geq 1$ F508del & NCT04043806 & Recruiting & $\begin{array}{l}\text { Vertex } \\
\text { Pharmaceuticals }\end{array}$ \\
\hline ELX/TEZ/IVA & $\geq 12$ years & III & Potentiator/corrector & $\geq 1$ F508del & NCT03525574 & Active, not recruiting & $\begin{array}{l}\text { Vertex } \\
\text { Pharmaceuticals }\end{array}$ \\
\hline ELX/TEZ/IVA & $\geq 12$ years & III & Potentiator/corrector & 2 F508del & NCT04105972 & Active, not recruiting & $\begin{array}{l}\text { Vertex } \\
\text { Pharmaceuticals }\end{array}$ \\
\hline ELX/EZ/IVA & $\geq 6$ years & III & Potentiator/corrector & 2 F508del or 1 F508del + 1 (F/F or F/MF) & NCT04183790 & Enrolling by invitation & $\begin{array}{l}\text { Vertex } \\
\text { Pharmaceuticals }\end{array}$ \\
\hline ELX/TEZ/IVA & $6-11$ years & III & Potentiator/corrector & 2 F508del or 1 F508del + 1 (F/F or FMF) & NCT03691779 & Active, not recruiting & $\begin{array}{l}\text { Vertex } \\
\text { Pharmaceuticals }\end{array}$ \\
\hline ELX/TEZ/IVA & $\geq 12$ years & II & Potentiator/corrector & Partial function mutations & NCT03506061 & Recruiting & Emory University \\
\hline POL6014 & $18-55$ years & $\mathrm{Ib} / \mathrm{Ila}$ & NEI & No specific mutation specified & NCT03748199 & Recruiting & $\begin{array}{l}\text { Santhera } \\
\text { Pharmaceuticals }\end{array}$ \\
\hline CHF 6333 & $\geq 18$ years & I & $\mathrm{NEI}$ & No specific mutation specified & NCT04010799 & Recruiting & $\begin{array}{l}\text { Chiesi } \\
\text { Farmaceutici S.p.A. }\end{array}$ \\
\hline PTI-801 & $18-55$ years & I & Corrector & 2 F508del & NCT03140527 & Recruiting & $\begin{array}{l}\text { Proteostasis } \\
\text { Therapeutics }\end{array}$ \\
\hline ABBV-3067 +/-ABBV-2222 & $\geq 18$ years & II & Potentiator/corrector & 2 F508del & NCT03969888 & Recruiting & AbbVie \\
\hline IONIS-ENaCRx & $18-50$ years & $\mathrm{Ib} / \mathrm{Ila}$ & ENaC blocker & No specific mutation specified & NCT03647228 & Recruiting & Ionis Pharmaceuticals \\
\hline ARO-ENaC & $18-55$ years & I/II & ENaC blocker & No specific mutation specified & NCT04375514 & Recruiting & $\begin{array}{l}\text { Arrowhead } \\
\text { Pharmaceuticals }\end{array}$ \\
\hline PTI-808/PTI-428/PTI-801 & 18 - 99 years & $\mathrm{Ib} / \mathrm{Ila}$ & $\begin{array}{l}\text { Potentiator/amplifier/ } \\
\text { corrector }\end{array}$ & $\geq 1$ F508del & NCT03251092 & $\begin{array}{l}\text { Active, } \\
\text { not recruiting }\end{array}$ & $\begin{array}{l}\text { Proteostasis } \\
\text { Therapeutics }\end{array}$ \\
\hline LAU-7b & $\geq 18$ years & II & Anti-inflammatory & No specific mutation specified & NCT03265288 & Recruiting & $\begin{array}{l}\text { Laurent } \\
\text { Pharmaceuticals }\end{array}$ \\
\hline BI 1265162 & $\geq 12$ years & II & ENaC blocker & $\geq 2$ CF mutations & NCT04059094 & Recruiting & $\begin{array}{l}\text { Boehringer } \\
\text { Ingelheim }\end{array}$ \\
\hline $\begin{array}{l}\text { Lenabasum } \\
\text { (20 mg; 5mg) }\end{array}$ & $\geq 12$ years & II & Anti-inflammatory & $\begin{array}{l}\text { No specific mutation } \\
\text { specified }\end{array}$ & NCT03451045 & $\begin{array}{l}\text { Active, not } \\
\text { recruiting }\end{array}$ & $\begin{array}{l}\text { Corbus } \\
\text { Pharmaceuticals }\end{array}$ \\
\hline $\begin{array}{l}\text { OligoG Dry } \\
\text { powder }\end{array}$ & $\geq 12$ years & II/III & Mucolytic & $\begin{array}{l}\text { No specific mutation } \\
\text { specified }\end{array}$ & NCT03698448 & Not yet recruiting & AlgiPharma AS \\
\hline $\begin{array}{l}\text { OligoG Dry } \\
\text { powder }\end{array}$ & $\geq 18$ years & II/III & Mucolytic & $\begin{array}{l}\text { No specific mutation } \\
\text { specified }\end{array}$ & NCT03822455 & Recruiting & AlgiPharma AS \\
\hline CB-280 & $\geq 18$ years & $\mathrm{Ib}$ & Anti-inflammatory & $\begin{array}{l}\text { No specific mutation } \\
\text { specified }\end{array}$ & NCT04279769 & Not yet recruiting & $\begin{array}{l}\text { Calithera } \\
\text { Biosciences }\end{array}$ \\
\hline MRT5005 & $\geq 18$ years & I/II & mRNA therapy & $\begin{array}{l}\text { Two Class I or II } \\
\text { mutations }\end{array}$ & NCT03375047 & Recruiting & Translate Bio \\
\hline VX-561//VA & $\geq 18$ years & II & Potentiator & $\begin{array}{l}1 \text { of either: G551D, G178R, } \\
\text { S549N, S549R, G551S, G1244E, } \\
\text { S1251N, S1255P, or G1349D }\end{array}$ & NCT03911713 & Recruiting & $\begin{array}{l}\text { Vertex } \\
\text { Pharmaceuticals }\end{array}$ \\
\hline
\end{tabular}


ppFEV $_{1}$ [122]. It continues to be tested in combination with PTI808 and PTI- 801 .

\section{Readthrough agents}

Attention has also been given to the potential usage of readthrough agents, a novel type of CFTR modulator, in patients with $\mathrm{CF}$ resulting from nonsense mutations. These are point mutations that result in the introduction of a premature termination codon (PTC), resulting in the production of a truncated and dysfunctional protein. This problem can be bypassed using the natural process of translational readthrough (TR). TR involves the suppression of a PTC which allows for translation to continue beyond that PTC, subsequently resulting in the development of the full-length protein. Readthrough agents seek to exploit this natural phenomenon to allow for the frequent production of a full-length, fully functional protein [123]. Such agents are therefore potentially useful for patients that have CF caused by nonsense mutations, a large subset of CFTR mutation Class I, that cause the production of a truncated CFTR protein [124]. One readthrough agent that had been given particular attention is Ataluren, a readthrough agent that has been shown to be effective in nonsense mutation Duchenne muscular dystrophy (nmDMD) and is currently being used to treat specific patients with nmDMD [125]. However, Phase III trials showed no significant difference in mean relative change in $\mathrm{FEV}_{1}$, or sweat chloride concentrations, when comparing Ataluren to placebo for the treatment of CF resulting from nonsense mutations, and clinical development was subsequently halted [126,127]. Another readthrough agent known as ELX-02 demonstrated that it was able to produce readthrough of PTCs whilst preserving the fidelity of native stop codons (NSCs) in preclinical studies [128]. It is currently in Phase II clinical trials in CF patients with G542X nonsense mutations (NCT04126473).

\section{$\mathrm{ENaC}$ as an alternative target}

There is also potential to target other channels that contribute to the pathogenesis of CF. Due to the heavy role that $\mathrm{ENaC}$ plays in the dehydration of ASL in CF, there has been a focus on the potential for $\mathrm{ENaC}$ as a therapeutic target, for which there are no current therapeutics. Theoretically, the therapeutic inhibition of ENaC can reduce the hyperabsorption of sodium ions seen in $\mathrm{CF}$, therefore rehydrating the ASL [129]. A variety of strategies can potentially be used to target $\mathrm{ENaC}$. One established strategy is to simply directly inhibit $\mathrm{ENaC}$, for which particular attention is being given to $\mathrm{BI} 1265162$, a highly potent $\mathrm{ENaC}$ inhibitor that has shown efficacy in preclinical testing. Phase I clinical trials also demonstrated that the molecule was safe and well tolerated. It is currently the only ENaC inhibitor in Phase II clinical trials, in which it must now demonstrate clinical efficacy [130].

Another strategy is to inhibit channel activating proteases (CAP) which increase $\mathrm{ENaC}$ activation in $\mathrm{CF}$ and therefore contribute to sodium hyperabsorption [131]. Camostat was a CAP inhibitor initially used to provide proof of concept that CAP inhibition can be used to attenuate ENaC function [132]. This has prompted the development of further compounds which may have the potential of replicating this effect. The two key inhibitors of ENaC-activating CAPs in development are QUB-TL1 and NAP858, both of which have been shown to improve ASL height and mucociliary clearance in preclinical studies. These compounds are only in pre-clinical development and their efficacy in vivo cannot be attested to [133].

Attention has also been given to the therapeutic potential of a protein called Short Palate Lung and Nasal Epithelial Clone 1 (SPLUNC1). SPLUNC1 is secreted by the airway epithelium and acts an autocrine inhibitor of $\mathrm{ENaC}$, a process which has the potential to be exploited [134]. SPX-101 is a key compound that was tested as a mimetic of SPLUNC1 as an attempt to replicate SPLUNC1's ENaC-inhibitory effects [135]. Preclinical studies showed that SPX-101 acts to internalise all of ENaC's subunits, leading to its inhibition [136]. Phase I trials on SPX-101 seemed to show that the compound was well tolerated and did not have systemic effects [137]. However, no further development on the compound is currently being undertaken and no other SPLUNC1 mimetics are currently in development [138]. Despite this, this is an area of inquiry that is relatively novel and therefore may have untapped potential.

Other lines of inquiry are looking into how $\mathrm{ENaC}$ production itself could be curtailed. One method to achieve this involves the usage of antisense oligonucleotides (ASOs). These have been shown to be efficacious in decreasing levels of mRNA that encode ENaC's subunits, even in the presence of mucus, and reversing CF-like symptoms in mouse models [139]. The only antisense therapeutic for $\mathrm{CF}$ in development is IONIS-ENaC-2.5Rx, which finished Phase I trials in June 2020 (NCT03647228). It was demonstrated to cause a mean $55.6 \%$ decrease in ENaC mRNA expression at a dose of $75 \mathrm{mg}$ in healthy patients, although full results are yet to be published [140]. As an alternative to ASOs, small interfering RNA (siRNA) can be delivered to the lung's epithelial cells. In preclinical studies, these siRNAs have demonstrated efficacy in reducing ENaC mRNA levels, resulting in a decrease in the number of ENaC channels [141]. The key siRNA-based therapeutic in development is ARO-ENaC, which is currently in Phase I clinical trials (NCT04375514).

\section{Gene delivery approaches}

In contrast to a mutation specific approach, genetic manipulation has the potential to treat $\mathrm{CF}$ patients with mutations in any class. This strategy involves introducing the correct copies of CFTR DNA into the epithelial cells in the airways [142]. There are two components that are required for this. The first is a normal copy of the CFTR gene, along with the required regulatory constructs, and the second is a transfer agent capable of efficient transfection.

The biggest challenge with this therapy will be how best to deliver the genetic material to the target cells. Lung cell turnover and the immune response have prevented many proposed vectors from delivering the CFTR gene into the epithelial cells $[143,144]$. Focus was previously placed on viral approaches such as adenoviruses, adeno-associated viruses and Sendai virus, but these have proved ineffective due to the inefficient transduction of the CFTR gene [145]. Lentiviruses look more favourable, as they have shown sufficient capacity for a CFTR expression cassette and greater transducing capabilities [146]. Additionally, unlike adenoviral vectors, lentiviral vectors display low immunogenicity and are more amenable to repeated dosing [147]. In individuals with severe lung disease who may not respond to existing prescribed CFTR modulators, such as those with nonsense mutations, lentiviral vectors may offer certain advantages. However, lentiviruses do not naturally possess the surface proteins capable of recognising receptors on respiratory epithelia. To get around this, the UK CF Gene Therapy Consortium has created a simian immunodeficiency virus (SIV) pseudotyped with $\mathrm{F}$ and $\mathrm{HN}$ envelope proteins taken from a Sendai virus [148]. Currently, the Consortium is trying to design a Phase I/IIa trial using nasal epithelium as a surrogate organ, which will allow for easy monitoring of gene expression and safety. As well as the lungs, CFTR is expressed in other organs and viruses may have potential in targeting these. This is because viruses can only deliver DNA to specific cell types. The subsequent positive effects in nutritional and metabolic requirements are likely to reduce clinical problems and significantly improve quality of life.

More recently, attention has shifted towards non-viral vectors. 
The most promising has been a formulation of Plasmid DNA expressing CFTR (pGM169) complexed with cationic liposome (GL67A). This biological agent was the first non-viral based gene therapy to undergo a clinical trial to detect functional changes. Following 12 monthly nebulised doses of PGM169/GL67A, there was a mild yet significant increase in $\mathrm{ppFEV}_{1}$ of $3.7 \%(0.1-7.3 \%$, $95 \%$ Confidence Intervals; $\mathrm{p}<0.05)$ and the therapy was generally well tolerated [149]. This is only a modest increase, especially when compared to other new drugs which show equal or better clinical outcomes [64-68,72-74,76-79]. It is therefore unlikely that the formulation will be suitable for use without further improvement in efficacy. In addition to this, increasing the frequency or dosage of this treatment could be explored, along with the addition of a CFTR potentiator. There were no treatment attributable adverse events seen, which could encourage the introduction of more potent vectors.

One of the main obstacles to the successful delivery of the DNA is the thick and tenacious mucus seen in $\mathrm{CF}$, which acts as a barrier against penetration by exogenous molecules [150]. The answer to this problem may lie with compressing DNA into small, dense structures called nanoparticles (NPs) [151,152]. NPs, due to their size, can feasibly be utilised to overcome this obstacle as they are less likely to be hindered by the mucus mesh. To further enhance penetration, NPs can be coated with the electrostatically neutral molecules like polyethylene glycol (PEG) to reduce electrostatic interactions with mucins. They can also be coated in mucolytics, agents that cleave mucin fibres, to enhance mucus penetration [153]. This ultimately results in a greater amount of the DNA reaching the target epithelial cells, enhancing the efficacy and viability of gene therapy [154].

\section{mRNA-based therapy}

Another new proposal is MRT5005. This is designed to restore CFTR function by delivering correct copies of CFTR-encoded mRNA, via a nebuliser, to the lung epithelial cells. It is the first clinical stage mRNA product candidate developed to treat all patients regardless of their underlying genetic mutation, including those with limited or no CFTR protein. A Phase I/II trial is now underway [155], with interim data of the first single ascending dose phase having been published [156]. Twelve Participants, eleven of whom had at least one copy of F508del mutation, were split into four groups receiving different dosages $(8,16$, and $24 \mathrm{mg}$ ) with one group receiving a placebo. In the eight-day period after dosing, the placebo group and $8 \mathrm{mg}$ dose group showed no marked improvement in $\mathrm{ppFEV}_{1}$. In the $16 \mathrm{mg}$ dose group, the mean maximum increase from baseline was $15.7 \%$ (5.8\% Standard Deviation), with two participants in this group on a CFTR modulator during this period. In the $24 \mathrm{mg}$ dose group, one patient experienced a maximum ppFEV 1 increase of $21.4 \%$, whilst two patients did not show any significant increase from their baseline.

\section{CRISPR/Cas9 gene editing}

CRISPR/Cas-9 based genome editing is a recent discovery with potential for correcting mutations in the CFTR gene [157]. Cas9 is a natural nuclease used for accurate DNA editing. It achieves this by complexing with a guide RNA (gRNA) that is specific to the target DNA, localising to the targeted DNA sequence, and then introducing a doubled-strand break (DSB) at the targeted site. This then activates the DNA DSB repair processes known as nonhomologous end-joining (NHEJ) and homology-directed repair (HDR), the latter of which most commonly utilises homologous recombination [158]. Donor DNA can then be provided, and this is used to repair the DSB, resulting in transgenic DNA [159]. Designing and testing gRNA has been met with high success rates and this technology has shown great promise for editing the human genome to treat CF [160].

Induced pluripotent stem cells with a CFTR mutation have been corrected using the CRISPR/Cas9 approach [161]. Stem cell niches have been described within the lungs, so it could be possible to obtain these cells from patients and correct the CFTR mutations, before reinserting them back into their environmental niches [157]. Alternatively, viral and non-viral vehicles could be used for delivering CRISPR/Cas9 into pulmonary epithelial cells, although transfection issues will have to be overcome.

A new tool in CRISPR technology has been the development of Cpf1, also known as Cas12a. This differs from Cas9 as Cpf1 gRNA is shorter and requires only one single gRNA molecule, compared to Cas9 that requires two gRNAs [162]. This makes it easier to synthesise gRNA in vitro and package it into vectors. Cpf1 also cuts DNA to leave 'sticky ends', which allows DNA insertion to be more controllable and easier to work with, unlike Cas9 which leaves 'blunt' ends [163]. This method has shown great success in other genetic conditions such as Duchenne muscular dystrophy, where Zhang et al. successfully corrected the faulty gene in both mouse models and cells derived from affected patients [164]. Maule et al. provided proof of concept for the use of Cas12a in editing CFTR mutations. A minigene model was used to demonstrate that Cas 12 a could be utilised to effectively repair two mutations in the CFTR gene that result in splicing defects. Primary airway epithelial cells were also used to validate the efficacy of Cas12a as delivered by a lentiviral vector [165].

Using intravenous administration for delivery is not preferential as vectors will reach the alveoli, an area devoted for gas exchange, and not the surface epithelium of the bronchial tree, where the CFTR protein is more frequently expressed [166]. Therefore, inhaled deliveries are viewed as a suitable strategy of delivering these vectors.

\section{Conclusion}

By managing the symptoms with established therapies, $\mathrm{CF}$ patients are living longer than ever before, and with the approval of CFTR modulators, this is only likely to increase. At this moment, several new treatments are being evaluated through clinical trials, which aim to improve lung function by directly interacting with CFTR or by altering its downstream effects. These may give rise to a new generation of therapies which reduce the symptomatic problems that are frequently seen amongst sufferers.

Gene manipulating techniques and new molecular targets are also being explored. The use of genome editing using CRISPR/Cas9 technology has great potential, although it is still in the early stages of development, with obstacles in deliverance still needing to be overcome. There should also be more attention drawn to other organs and glands expressing CFTR mutations, as this will have vast nutritional and metabolic benefits if targeted successfully. Overall, there has been significant progress in the treatment of cystic fibrosis by attempting to restore the airways to a natural phenotype, either through restoring the function of existing CFTR proteins, modifying epithelial cells to produce normal CFTR, or by targeting alternative channels.

\section{Acknowledgements}

We would like to acknowledge Katie Jaques and William Secrett for proof-reading and editing. 


\author{
Abbreviations \\ CF: $\quad$ cystic fibrosis; \\ CFTR: $\quad$ cystic fibrosis transmembrane conductance regulator; \\ NBD: nucleotide binding domain; \\ ENaC: epithelial sodium channel; \\ PNEC: pulmonary neuroendocrine cells; \\ ASL: $\quad$ airway surface liquid; \\ PCL: periciliary layer; \\ ML: $\quad$ mucus layer; \\ IRT: immunoreactive trypsinogen; \\ NPD: $\quad$ nasal potential difference; \\ $\mathrm{FEV}_{1}$ : forced expiratory volume in 1 second; \\ FEF: forced expiratory flow; \\ FVC: forced vital capacity; \\ $\mathrm{ppFEV}_{1}$ : percent predicted forced expiratory volume in \\ one second; \\ ICS: inhaled corticosteroids; \\ PTC: premature termination codon; \\ TR: $\quad$ translational readthrough; \\ nmDMD: nonsense mutation Duchenne muscular dystrophy; \\ NSC: $\quad$ native stop codons; \\ CAP: channel activating proteases; \\ SPLUNC1: short palate lung and nasal epithelial clone 1; \\ ASO: antisense oligonucleotides; \\ siRNA: small interfering RNA; \\ SIV: $\quad$ simian immunodeficiency virus; \\ NP: nanoparticle; \\ PEG: $\quad$ polyethylene glycol; \\ gRNA: guide RNA; \\ DSB: doubled-strand break; \\ NHEJ: nonhomologous end-joining; \\ HDR: homology-directed repair.
}

\section{References}

1. Kreda SM, Davis CW, Rose MC. CFTR, mucins, and mucus obstruction in cystic fibrosis. Cold Spring Harb Perspect Med 2012;2:a009589.

2. Filkins LM, O'Toole GA. Cystic fibrosis lung infections: Polymicrobial, complex, and hard to treat. PLoS Pathog 2015; 11:e1005258.

3. Lyczak JB, Cannon CL, Pier GB. Lung infections associated with cystic fibrosis. Clin Microbiol Rev 2002;15:194-222.

4. Keogh RH, Szczesniak R, Taylor-Robinson D, Bilton D. Upto-date and projected estimates of survival for people with cystic fibrosis using baseline characteristics: A longitudinal study using UK patient registry data. J Cyst Fibros 2018;17:218-27.

5. European Cystic Fibrosis Society Patient Registry. Database for $\mathrm{CF}$ information in 35 participating countries. Available from: https://www.ecfs.eu/ecfspr

6. US CF Foundation Registry. Annual Reports for detailed information on CF Care and treatment outcomes. Available from: https://www.cff.org/Research/Researcher-Resources/ Patient-Registry/

7. Australian Cystic Fibrosis Data Registry. Annual Reports for Health outcomes and information. Available from: https://www.cysticfibrosis.org.au/dataregistry

8. Mirtajani SB, Farnia P, Hassanzad M, Ghanavi J, Farnia P, Velayati AA. Geographical distribution of cystic fibrosis; The past 70 years of data analyzis. Biomed Biotech Res J 2017;1:105-12.

9. ECFS Patient Registry Annual Data Report 2017. PDF
Available from: https://www.ecfs.eu/sites/default/files/generalcontent-images/working-groups/ecfs-patient-registry/ECFSPR Report2017_v1.3.pdf

10. Burgel PR, Bellis G, Olesen HV, Viviani L, Zolin A, Blasi F, et al. Future trends in cystic fibrosis demography in 34 European countries. Eur Respir J 2015;46:133-41.

11. Lao O, Andrés AM, Mateu E, Bertranpetit J, Calafell F. Spatial patterns of cystic fibrosis mutation spectra in European populations. Eur J Hum Genet 2003;11:385-94.

12. Kosorok MR, Wei WH, Farrell PM. The incidence of cystic fibrosis. Stat Med 1996;15:449-62.

13. US Cystic Fibrosis Foundation. Registry Annual Data Report 2018. Available from: https://www.cff.org/Research/ Researcher-Resources/Patient-Registry/2018-Patient-RegistryAnnual-Data-Report.pdf

14. Davies JC, Geddes DM, Alton EW. Gene therapy for cystic fibrosis. J Gene Med 2001;3:409-17.

15. Elborn JS. Cystic fibrosis. Lancet 2016;388:2519-31.

16. Ma J, Zhao J, Drumm ML, Xie J, Davis PB. Function of the R domain in the cystic fibrosis transmembrane conductance regulator chloride channel. J Biol Chem 1997;272:28133-141.

17. Tang L, Fatehi M, Linsdell P. Mechanism of direct bicarbonate transport by the CFTR anion channel. J Cyst Fibros 2009;8:115-21.

18. Ehre C, Ridley C, Thornton DJ. Cystic fibrosis: an inherited disease affecting mucin-producing organs. Int J Biochem Cell Biol 2014;52:136-45.

19. Mall MA, Hartl D. CFTR: cystic fibrosis and beyond. Eur Respir J 2014;44:1042-054.

20. Cutting GR. Cystic fibrosis genetics: from molecular understanding to clinical application. Nat Rev Genet 2015;16:45-56.

21. Tam A, Wadsworth S, Dorscheid D, Man SF, Sin DD. The airway epithelium: more than just a structural barrier. Ther Adv Respir Dis 2011;5:255-73.

22. Montoro DT, Haber AL, Biton M, Vinarsky V, Lin B, Birket SE, et al. A revised airway epithelial hierarchy includes CFTRexpressing ionocytes. Nature 2018;560:319-324.

23. Moore PJ, Tarran R. The epithelial sodium channel (ENaC) as a therapeutic target for cystic fibrosis lung disease. Expert Opin Ther Targets 2018;22:687-701.

24. Saint-Criq V, Gray MA. Role of CFTR in epithelial physiology. Cell Mol Life Sci 2017;74:93-115.

25. Derichs N, Jin BJ, Song Y, Finkbeiner WE, Verkman AS. Hyperviscous airway periciliary and mucous liquid layers in cystic fibrosis measured by confocal fluorescence photobleaching. FASEB J 2011;25:2325-32.

26. Haq IJ, Gray MA, Garnett JP, Ward C, Brodli M. Airway surface liquid homeostasis in cystic fibrosis: pathophysiology and therapeutic targets. Thorax 2016;71:284-7.

27. Hanukoglu I, Boggula VR, Vaknine H, Sharma S, Kleyman T, Hanukoglu A. Expression of epithelial sodium channel (ENaC) and CFTR in the human epidermis and epidermal appendages. Histochem Cell Biol 2017;147:733-48.

28. Al Sinani S, Al-Mulaabed S, Al Naamani K, Sultan R. Cystic fibrosis liver disease: Know more. Oman Med J 2019;34:4829.

29. de Souza DAS, Faucz FR, Pereira-Ferrari L, Sotomaior VS, Raskin Sl. Congenital bilateral absence of the vas deferens as an atypical form of cystic fibrosis: Reproductive implications and genetic counseling. Andrology 2018;6:127-35.

30. Cystic Fibrosis Mutation Database Statistics [Internet]. CFMDB statistics. Accessed: October 2020. Available from: http://www.genet.sickkids.on.ca/StatisticsPage.html

31. Karimi N, Pour AB, Alibakhshi R, Almasi S. Haplotype analysis of the CFTR gene on normal and mutant CFTR genes. 
Mutat Res 2020;821:111708

32. Castellani C, Cuppens H, Macek M Jr, Cassiman JJ, Kerem E, Durie $\mathrm{P}$, et al. Consensus on the use and interpretation of cystic fibrosis mutation analysis in clinical practice. J Cyst Fibros 2008;7:179-96.

33. Fraser-Pitt D, O’Neil D. Cystic fibrosis-a multiorgan protein misfolding disease. Future Sci OA 2015;1:FSO57.

34. Castellani C, Massie J. Newborn screening and carrier screening for cystic fibrosis: alternative or complementary? Eur Respir J 2014;43:20-3.

35. Farrell PM, Rosenstein BJ, White TB, Accurso FJ, Castellani C, Cutting GR, et al. Guidelines for diagnosis of cystic fibrosis in newborn through older adults: Cystic Fibrosis Foundation Report. J Pediatr 2008;153:S4-14.

36. Mishra A, Greaves R, Massie J. The relevance of sweat testing for the diagnosis of cystic fibrosis in the genomic era. Clin Biochem Rev 2005;26:135-53.

37. Shaw J, Scotchman E, Chandler N, et al. PREIMPLANTATION GENETIC TESTING: Non-invasive prenatal testing for aneuploidy, copy-number variants and single-gene disorders. Reproduction 2020;160:A1-A11.

38. Rowe SM, Clancy JP, Wilschanski M. Nasal potential difference measurements to assess CFTR ion channel activity. Methods Mol Biol 2011;741:69-86.

39. Long JM, Fauset-Jones J, Dixon MJ, Worthington-Riley D, Sharma V, Patel L, et al. Annual review hospital visits for patients with cystic fibrosis. J R Soc Med 2001;94(s40):S126.

40. Kamal N, Surana P, Koh C. Liver disease in patients with cystic fibrosis. Curr Opin Gastroenterol 2018;34:146-51.

41. Bishay L, Sawicki G. Strategies to optimize treatment adherence in adolescent patients with cystic fibrosis. Adolesc Health Med Ther 2016;7:117-24.

42. McVean RJ, Orr A, Webb AK, Bradbury A, Kay L, Philips E, et al. Treatment of urinary incontinence in cystic fibrosis. J Cyst Fibros 2003;2:171-6.

43. Agent $P$, Parrott $H$. Inhaled therapy in cystic fibrosis: agents, devices and regimens. Breathe (Sheff) 2015;11:110-8.

44. Scherer TA, Spengler CM, Owassapian D, Imhof E, Buotellier U. Respiratory muscle endurance training in chronic obstructive pulmonary disease: impact on exercise capacity, dyspnea, and quality of life. Am J Respir Crit Care Med 2000;162:1709-14.

45. Button BM, Button B. Structure and function of the mucus clearance system of the lung. Cold Spring Harb Perspect Med 2013;3:a009720.

46. Mauch RM, Kmit AH, Marson FA, Levy CE, Barros-Filho A, Ribeiro JD. Association of growth and nutritional parameters with pulmonary function in cystic fibrosis: a literature review. Rev Paul Pediatr 2016;34:503-9.

47. Lai HJ, Shoff SM. Classification of malnutrition in cystic fibrosis: implications for evaluating and benchmarking clinical practice performance. Am J Clin Nutr 2008;88:161-6.

48. Cohen-Cymberknoh M, Shoseyov D, Kerem E. Managing cystic fibrosis: strategies that increase life expectancy and improve quality of life. Am J Respir Crit Care Med 2011;183:1463-71.

49. Parsons HG, Beaudry P, Dumas A, Pencharz PB. Energy needs and growth in children with cystic fibrosis. J Pediatr Gastroenterol Nutr 1983;2:44-9.

50. Quittner AL, Goldbeck L, Abbott J, Duff A, Lambrecht P, Solé A, et al. Prevalence of depression and anxiety in patients with cystic fibrosis and parent caregivers: Results of The International Depression Epidemiological Study across nine countries. Thorax 2014;69:1090-7.

51. Quittner AL, Abbott J, Georgiopoulos AM, Goldbeck L, Smith
B, Hempstead SE, et al. International Committee on mental health in cystic Fibrosis: Cystic fibrosis Foundation and European cystic fibrosis Society consensus statements for screening and treating depression and anxiety. Thorax 2016;71:26-34.

52. Martin A, Rief W, Klaiberg A, Braehler E. Validity of the brief patient health questionnaire mood scale (PHQ-9) in the general population. Gen Hosp Psychiatry 2006;28:71-7.

53. Dierker LC, Albano AM, Clarke GN, Heimberg RG, Kendall PC, Merikangas KR, et al. Screening for anxiety and depression in early adolescence. J Am Acad Child Adolesc Psychiatry 2001;40:929-36.

54. Eisenberg D, Gollust SE, Golberstein E, Hefner JL. Prevalence and correlates of depression, anxiety, and suicidality among university students. Am J Orthopsychiatry 2007;77:534-42.

55. National Institute for Health and Care Excellence (NICE). Cystic fibrosis: diagnosis and management - NICE guideline [NG78]. Available from: https://www.nice.org.uk/guidance/ ng78/chapter/recommendations

56. Elkins MR, Bye PT. Mechanisms and applications of hypertonic saline. J R Soc Med 2011;104:S2-5.

57. Ratjen F, Davis SD, Stanojevic S, Kronmal RA, Hinckley Stukovsky KD, Jorgensen N, et al. Inhaled hypertonic saline in preschool children with cystic fibrosis (SHIP): a multicentre, randomised, double-blind, placebo-controlled trial. Lancet Respir Med 2019;7:802-9.

58. Pressler T. Review of recombinant human deoxyribonuclease (rhDNase) in the management of patients with cystic fibrosis. Biol Targets Ther 2008;2:611.

59. Suri R, Metcalfe C, Lees B, Grieve R, Flather M, Normand C, et al. Comparison of hypertonic saline and alternate-day or daily recombinant human deoxyribonuclease in children with cystic fibrosis: a randomised trial. Lancet 2001;358:1316-21.

60. Suri R, Grieve R, Normand C, Metcalfe C, Thompson S, Wallis C, Bush A. Effects of hypertonic saline, alternate day and daily rhDNase on healthcare use, costs and outcomes in children with cystic fibrosis. Thorax 2002;57:841-6.

61. King M, Dasgupta B, Tomkiewicz RP, Brown NE. Rheology of cystic fibrosis sputum after in vitro treatment with hypertonic saline alone and in combination with recombinant human deoxyribonuclease I. Am J Respir Crit Care Med 1997;156:173-7.

62. Flume PA, Aitken ML, Bilton D, Agent P, Charlton B, Forster E, et al. Optimising inhaled mannitol for cystic fibrosis in an adult population. Breathe Sheff Engl 2015;11:39-48.

63. Trapnell BC. Inhaled dry powder mannitol: a solution for cystic fibrosis. Am J Respir Crit Care Med 2012;185:596-8.

64. Moss RB, Flume PA, Elborn JS, Cooke J, Rowe SM, McColley SA, et al. Efficacy and safety of ivacaftor in patients with cystic fibrosis who have an arg117his-CFTR mutation: a doubleblind, randomised controlled trial. Lancet Respir Med 2015;3:524-33.

65. De Boeck K, Munck A, Walker S, Faro A, Hiatt P, Gilmartin $\mathrm{G}$, et al. Efficacy and safety of ivacaftor in patients with cystic fibrosis and a non-G551D gating mutation. J Cyst Fibros 2014;13:674-80.

66. Davies JC, Wainwright CE, Canny GJ, Chilvers MA, Howenstine MS, Munck A, et al. Efficacy and safety of ivacaftor in patients aged 6 to 11 years with cystic fibrosis with a G551D mutation. Am J Respir Crit Care Med 2013; 187:1219-25.

67. McKone EF, Borowitz D, Devinek P, Griese M, Konstan MW, Wainwright $\mathrm{C}$, et al. Long-term safety and efficacy of ivacaftor in patients with cystic fibrosis who have the Gly551Asp-CFTR mutation: a phase 3, open-label extension study (PERSIST). Lancet Respir Med 2014;2:902-10. 
68. Ramsey BW, Davies J, McElvaney NG, Tullis E, Bell SC, Dřevínek $\mathrm{P}$, et al. A CFTR potentiator in patients with cystic fibrosis and the G551D mutation. N Engl J Med 2011; 365:1663-72.

69. McNamara JJ, McColley SA, Marigowda G, Liu F, Tian S, Owen CA, et al. Safety, pharmacokinetics and pharmacodynamics of lumacaftor and ivacaftor combination therapy in children aged 2-5 years with cystic fibrosis homozygous for F508del-CFTR: ah open-label phase 3 study. Lancet Respir Med 2019;7:325-35.

70. Milla CE, Ratjen F, Marigowda G, Liu F, Waltz D, Rosenfeld $\mathrm{M}$, et al. Lumacaftor/ivacaftor in patients aged 6-11 years with cystic fibrosis and homozygous for F508del-CFTR. Am J Respir Crit Care Med 2017;195:912-20.

71. Taylor-Cousar JL, Jain M, Barto TL, Haddad T, Atkinson J, Tian S, et al. Lumacaftor/ivacaftor in patients with cystic fibrosis and advanced lung disease homozygous for F508delCFTR. J Cyst Fibros 2018;17:228-35.

72. Elborn JS, Ramsey BW, Boyle MP, Konstan MW, Huang W, Marigowda G, et al. Efficacy and safety of lumacaftor/ivacaftor combination therapy in patients with cystic fibrosis homozygous for phe508del CFTR by pulmonary function subgroup: a pooled analysis. Lancet Respir Med 2016;4:61726.

73. Ratjen F, Hug C, Marigowda G, Tian S, Huang X, Stanojevic $\mathrm{S}$, et al. Efficacy and safety of lumacaftor and ivacaftor in patients aged 6-11 with cystic fibrosis homozygous for F508del-CFTR: a randomized, placebo-controlled phase 3 trial. Lancet Respir Med 2017;5:557-67.

74. Konstan MW, McKone EF, Moss RB, Marigowda G, Tian S, Waltz D, et al. Assessment of safety and efficacy of long-term treatment with combination lumacaftor and ivacaftor therapy in patients with cystic fibrosis homozygous for the F508delCFTR mutation (PROGRESS): a phase 3, extension study. Lancet Res Med 2017;5:107-18.

75. Walker S, Glume P, McNamara J, Solomon M, Chilvers M, Chmiel J, et al. A phase 3 study of tezacaftor in combination with ivacaftor in children aged 6 through 11 years with cystic fibrosis. J Cyst Fibros 2019:18:708-13.

76. Taylor-Cousar JL, Munck A, McKone EF, van der Ent CK, Moeller A, Simard C, et al. Tezacaftor-Ivacaftor in patients with cystic fibrosis homozygous for Phe508del. N Eng J Med 2017;377:2013-23.

77. Rowe SM, Daines C, Ringshausen FC, Kerem E, Wilson J, Tullis E, et al. Tezacaftor-Ivacaftor in residual-function heterozygotes with cystic fibrosis. $N$ Eng J Med 2017;377:2024-34.

78. Middleton PG, Mall MA, Drevínek P, Lands LC, McKone EF, Polineni D, et al. Elexacaftor-tezacaftor-ivacaftor for cystic fibrosis with a single phe508del allele. N Eng J Med 2019;381:1809-19.

79. Heijerman HGM, McKone EF, Downey DG, Van Braeckel E, Rowe SM, Tullis E, et al. Efficacy and safety of the elexacaftor plus tezacaftor plus ivacaftor combination regimen in people with cystic fibrosis homozygous for the F508del mutation: a double-blind, randomised, phase 3 trial. Lancet 2019;394: 1940-8.

80. Csanády L, Töröcsik B. Cystic fibrosis drug ivacaftor stimulates CFTR channels at picomolar concentrations. Elife 2019;8:e46450.

81. Guigui S, Wang J, Cohen RI. The use of ivacaftor in CFTR mutations resulting in residual functioning protein. Resp Med Case Rep 2016;19:193-5.

82. Carlile GW, Yang Q, Matthes E, Liao J, Radinovic S, Miyamoto, et al. A novel triple combination of pharmacological chaperones improves F508del-CFTR correction. Sci Rep
2018;8:11404.

83. Clancy JP. Rapid therapeutic advances in CFTR modulator science. Pediatr Pulmonol 2018;53:S4-11.

84. Ridley K, Condren M. Elexacaftor-Tezacaftor-Ivacaftor: The first triple-combination cystic fibrosis transmembrane conductance regulator modulating therapy. J Pediatr Pharmacol Ther 2020;25:192-7.

85. LiverTox: Clinical and Research Information on Drug-Induced Liver Injury [Internet]. Bethesda (MD): National Institute of Diabetes and Digestive and Kidney Diseases; 2012. Cystic Fibrosis Agents. Available from: https://www.ncbi. nlm.nih. gov/books/NBK547889/

86. Chaudary N. Triplet CFTR modulators: future prospects for treatment of cystic fibrosis. Ther Clin Risk Manag 2018;14:2375-2383.

87. Vertex Pharmaceuticals, Inc. Kalydeco [Product Monograph] 2012. Laval, Quebec: Available from: https://pi.vrtx.com/files/ uspi_ivacaftor.pdf

88. Vertex Pharmaceuticals, Inc. Orkambi [Product Monograph] 2015. Laval, Quebec: Available from: https://pi.vrtx.com/files/ uspi_lumacaftor_ivacaftor.pdf

89. Vertex Pharmaceuticals, Inc. Symdeko [Product Monograph] 2018. Laval, Quebec: Available from: https://pi.vrtx.com/files/ uspi tezacaftor ivacaftor.pdf

90. Vertex Pharmaceuticals, Inc. Trikafta [Product Monograph] 2019. Laval, Quebec: Available from: https://pi.vrtx.com/files/ uspi_elexacaftor_tezacaftor_ivacaftor.pdf

91. European Medicine Agency. Pending EC decision for Ivacaftor - Committee for Medicinal Products for Human Use (CHMP). Available from: https://www.ema.europa.eu/en/ medicines/ human/summaries-opinion/kalydeco-3\#key-facts-section

92. European Medicine Agency. Pending EC decision for Symkevi - Committee for Medicinal Products for Human Use (CHMP). Available from: https://www.ema.europa.eu/en/ medicines /human/summaries-opinion/symkevi-0

93. Flume PA, O'Sullivan BP, Robinson KA, Goss CH, Mogayzel PJ Jr, Willey-Courand B, et al. Cystic fibrosis pulmonary guidelines: chronic medications for maintenance of lung health. Am J Respir Crit Care Med 2007;176:957-69.

94. De Rose V, Molloy K, Gohy S, Pilette C, Greene CM. Airway epithelium dysfunction in cystic fibrosis and COPD. Mediators Inflamm 2018;2018:1309746.

95. Balfour-Lynn IM, Elborn JS. "CF asthma": what is it and what do we do about it? Thorax 2002;57:742-8.

96. Dahl M, Tybjærg-Hansen A, Lange P, Nordestgaard BG. DeltaF508 heterozygosity in cystic fibrosis and susceptibility to asthma. Lancet 1998;351:1911-3. Erratum in Lancet 1998;352:1230.

97. Schroeder SA, Gaughan DM, Swift M. Protection against bronchial asthma by CFTR delta F508 mutation: a heterozygote advantage in cystic fibrosis. Nat Med 1995;1:7035.

98. Halfhide C, Evans HJ, Couriel J. Inhaled bronchodilators for cystic fibrosis. Cochrane Database Syst Rev 2005:CD003428.

99. Smith S, Edwards CT. Long-acting inhaled bronchodilators for cystic fibrosis. Cochrane Database Syst Rev 2017:CD012102.

100. Barry PJ, Flume PA. Bronchodilators in cystic fibrosis: a critical analysis. Expert Rev Respir Med 2017;11:13-20.

101. Eckrich J, Zissler UM, Serve F, Leutz P, Smaczny C, SchmittGrohé S, et al. Airway inflammation in mild cystic fibrosis. J Cyst Fibros 2017; 16:107-15.

102. Konstantinos Katsoulis K, Kostikas K, Kontakiotis T. Techniques for assessing small airways function: Possible applications in asthma and COPD. Respir Med 2016;119:e29.

103. Scichilone N, Contoli M, Paleari D, Pirina P, Rossi A, 
Sanguinetti CM, et al. Assessing and accessing the small airways; implications for asthma management. Pulm Pharmacol Ther 2013;26:172-9.

104. Balfour-Lynn IM, Welch K. Inhaled corticosteroids for cystic fibrosis. Cochrane Database Syst Rev 2016:CD001915.

105. De Boeck K, De Baets F, Malfroot A, Desager K, Mouchet F, Proesmans M. Do inhaled corticosteroids impair long-term growth in prepubertal cystic fibrosis patients? Eur J Pediatr 2007; 166:23-8.

106. Latorre M, Novelli F, Vagheggini B, Braido F, Papi A, Sanduzzi A, et al. Differences in the efficacy and safety among inhaled corticosteroids (ICS)/long-acting beta2-agonists (LABA) combinations in the treatment of chronic obstructive pulmonary disease (COPD): Role of ICS. Pulm Pharmacol Ther 2015;30:44-50.

107. Lynch JP III, Sayah DM, Belperio JA, Weigt SS. Lung transplantation for cystic fibrosis: results, indications, complications, and controversies. Semin Respir Crit Care Med 2015;36:299-320.

108. Meachery G, De Soyza A, Nicholson A, Parry G, Hasan A, Tocewicz K, et al. Outcomes of lung transplantation for cystic fibrosis in a large UK cohort. Thorax 2008;63:725-31.

109. Davies JC, Alton EWF, Bush A. Cystic fibrosis. BMJ 2007;335:1255-9.

110. Coburn B, Wang PW, Diaz Caballero J, Clark ST, Brahma V, Donaldson S, et al. Lung microbiota across age and disease stage in cystic fibrosis. Sci Rep 2015;5:10241.

111. Huang YJ, LiPuma JJ. The microbiome in cystic fibrosis. Clin Chest Med 2016;37:59-67.

112. Bhagirath AY, Li Y, Somayajula D, Dadashi M, Badr S, Duan K. Cystic fibrosis lung environment and Pseudomonas aeruginosa infection. BMC Pulm Med 2016;16:174.

113. Coutinho HDM, Falcao-Silva VS, Goncalves GF. Pulmonary bacterial pathogens in cystic fibrosis patients and antibiotic therapy: a tool for the health workers. Int Arch Med 2008;1:24.

114. Brooke JS. Stenotrophomonas maltophilia: An emerging global opportunistic pathogen. Clin Microbiol Rev 2012;25:2-41.

115. Tamma PD, Cosgrove SE, Maragakis LL. Combination therapy for treatment of infections with gram-negative bacteria. Clin Microbiol Rev 2012;25:450-70.

116. Peloquin CA, Berning SE, Nitta AT, Simone PM, Goble M, Huitt GA, et al. Aminoglycoside toxicity: daily versus thriceweekly dosing for treatment of mycobacterial diseases. Clin Infect Dis 2004;38:1538-44.

117. Petkova M, Gesson C, De Vos S, Conrath K, Corveleyn S, Geller D, et al. safety, tolerability and pharmacokinetics of a novel CFTR potentiator GLPG3067 in healthy volunteers. Galapagos Biotech 2017 Poster. Available at: https://www.glpg.com/docs/view/59fc5ef4102ec-en

118. Singh AK, Fan Y, Balut C, Alani S, Manelli AM, Swenses AM, et al. Biological characterization of F508delCFTR protein processing by the CFTR corrector ABBV-2222/GLPG2222. J Pharmacol Exp Ther 2020;372:107-18.

119. Lopes-Pacheco M. CFTR modulators: The changing face of cystic fibrosis in the era of precision medicine. Front Pharmacol 2020;10:1662.

120. Proteostasis Therapeautics, Inc. Recent positive phase 2 and ex vivo organoid study data support initiation of MORE and CHOICES trials in 2020 proteostatis therapeutics regulatory update 2020. Available from: https://www.prnewswire. com/news-releases/proteostasis-therapeutics-regulatory-updatefollowing-scientific-advice-meeting-with-mhra-300985498.ht $\mathrm{ml}$

121. Molinski SV, Ahmadi S, Ip W, Ouyang H, Villella A, Miller JP, et al. Orkambi ${ }^{\circledR}$ and amplifier co-therapy improves function from a rare CFTR mutation in gene-edited cells and patient tissue. EMBO Mol Med 2017;9:1224-43.

122. Matos AM, Matos P. Combination therapy in Phe508del CFTR: how many will be enough? J Lung Health Dis 2018;2:9-16.

123. Dabrowski M, Bukowy-Bieryllo Z, Zietkiewicz E. Advances in therapeutic use of a drug-stimulated translational readthrough of premature termination codons. Mol Med 2018;24:25.

124. Wilschanski M. Class 1 CF Mutations. Front Pharmacol 2012; $3: 117$.

125. Mercuri E, Muntoni F, Osorio AN, Tulinius M, Buccella F, Morgenroth LP, et al. Safety and effectiveness of ataluren: comparison of results from the STRIDE Registry and CINRG DMD Natural History Study. J Comp Eff Res 2020;9:341-60.

126. Abidi NZ, Haq IJ, Gardner AI, Brodlie M. Ataluren in cystic fibrosis: development, clinical studies and where are we now? Expert Opin Pharmacother 2017;18:1363-71.

127. Aslam AA, Higgins C, Sinha IP, et al. Ataluren and similar compounds (specific therapies for premature termination codon class I mutations) for cystic fibrosis. Cochrane Database Systc Rev2017;1:CD012040. rawford DK, Alroy I, Sharpe N, Goddeeris MM, Williams G. Premature versus native stop codon read-through by ELX-02. J Pharmacol Exp Ther 2020;374:264-72.

128. Moore PJ, Robert Tarran R. The epithelial sodium channel $(\mathrm{ENaC})$ as a therapeutic target for cystic fibrosis lung disease. Expert Opin Ther Targets 2018;22:8:687-701.

129. Mall MA. ENaC inhibition in cystic fibrosis: potential role in the new era of CFTR modulator therapies. Eur Respir J 2020;2000946.

130. Reihill JA, Walker B, Hamilton RA, Ferguson TE, Elborn JS, Stutts MJ, et al. Inhibition of protease-epithelial sodium channel signaling improves mucociliary function in cystic fibrosis airways. Am J Respir Crit Care Med 2016;194:701-10.

131. Rowe SM, Reeves G, Hathorne H, Solomon GM, Abbi S, Renard D, et al. Reduced sodium transport with nasal administration of the prostasin inhibitor camostat in subjects with cystic fibrosis. Chest 2013;144:200-7.

132. Strug LJ, Stephenson AL, Panjwani N, Harris A. Recent advances in developing therapeutics for cystic fibrosis. Hum Molr Genet 2018;27:R173-86.

133. Hobbs CA, Blanchard MG, Alijevic O, Da Tan C, Kellenberge $\mathrm{S}$, Bencharit $\mathrm{S}$, et al. Identification of the SPLUNC1 ENaCinhibitory domain yields novel strategies to treat sodium hyperabsorption in cystic fibrosis airway epithelial cultures. Am J Physiol Lung Cell Mol Physiol 2014;1;306:L708.

134. Lennox A, Myerburg MM. SPX-101 is a promising and novel nebulized ENaC inhibitor. Am J Respir Crit Care Med 2017;196:671-2.

135. Scott DW, Walker MP, Sesma J, Wu B, Stuhlmiller TJ, Sabater JR, et al. SPX-101 is a novel epithelial sodium channel-targeted therapeutic for cystic fibrosis that restores mucus transport. Am J Respir Crit Care Med 2017;196:734-44.

136. Couroux P, Farias P, Rizvi L, Griffin K, Hudson C, Crowder $\mathrm{T}$, et al. First clinical trials of novel ENaC targeting therapy, SPX-101, in healthy volunteers and adults with cystic fibrosis. Pulm Pharmacol Ther 2019;58:101819.

137. Cystic Fibrosis Foundation. Drug Development Pipeline: SPX101. Available from: https://www.cff.org/Trials/Pipeline/ details/10128/SPX-101

138. Crosby JR, Zhao C, Jiang C, Bai D, Katz M, Greenlee S, et al. Inhaled $\mathrm{ENaC}$ antisense oligonucleotide ameliorates cystic fibrosis-like lung disease in mice. J Cyst Fibros 2017;16:67180.

139. Ionis Pharmaceuticals, Inc. Ionis' inhaled antisense medicine demonstrates potential as a novel treatment for cystic fibrosis. Ionis Pharmaceuticals, Inc. Update 2020. Available from: 
https://ir.ionispharma.com/news-releases/news-releasedetails/c-o-r-r-e-c-t-i-o-n-ionis-pharmaceuticals-inc-0

140. Manunta MDI, Tagalakis AD, Attwood M, Aldossary AM, Barnes JL, Munye MM, et al. Delivery of ENaC siRNA to epithelial cells mediated by a targeted nanocomplex: a therapeutic strategy for cystic fibrosis. Sci Rep 2017;7:700.

141. Burney TJ, Davies JC. Gene therapy for the treatment of cystic fibrosis. Appl Clin Genet 2012;5:29-36.

142. Karda R, Buckley SMK, Waddington SN. Gene therapy with adeno-associated virus for cystic fibrosis. Am J Respir Crit Care Med 2016;193:234-6.

143. Donnelley M, Parsons DW. Gene therapy for cystic fibrosis lung disease: overcoming the barriers to translation to the clinic. Front Pharmacol 2018;9,1381.

144. Griesenbach U, Inoue M, Hasegawa M, Alton EWFW. Viral vectors for cystic fibrosis gene therapy: What does the future hold? Dove Press 2010;2:159-71.

145. Naldini L, Blomer U, Gage FH, Trono D, Verma IM. Efficient transfer, integration, and sustained long-term expression of the transgene in adult rat brains injected with a lentiviral vector. Proc Natl Acad Sci USA 1996;93:11382-8.

146. Griesenbach U, Inoue M, Meng C, Farley R, Chan M, Newman $\mathrm{NK}$, et al. Assessment of F/HN-pseudotyped lentivirus as a clinically relevant vector for lung gene therapy. Am J Respir Crit Care Med 2012;186,846-56.

147. Moradali MF, Ghods S, Rehm BH. Pseudomonas aeruginosa lifestyle: a paradigm for adaptation, survival, and persistence. Front Cell Infect Microbiol 2017;7:39.

148. Alton E, Armstrong DK, Ashby D, Bayfield KJ, Bilton D, Bloomfield EVm et al. Repeated nebulisation of non-viral CFTR gene therapy in patients with cystic fibrosis: a randomised, double-blind, placebo-controlled, phase $2 \mathrm{~b}$ trial. Lancet Respir Med 2015;3-:684-91.

149. Lai SK, Wang YY, Hanes J. Mucus-penetrating nanoparticles for drug and gene delivery to mucosal tissues. Adv Drug Deliv Rev 2009;61:158-71.

150. Suk JS, Lai SK, Boylan NJ, Dawson MR, Boyle MP, Hanes J. Rapid transport of muco-inert nanoparticles in cystic fibrosis sputum treated with $\mathrm{N}$-acetyl cysteine. Nanomedicine (Lond) 2011;6:365-75.

151. Lababidi N, Sigal V, Koenneke A, Schwarzkopf K, Manz A, Schneider M. Microfluidics as tool to prepare size-tunable PLGA nanoparticles with high curcumin encapsulation for efficient mucus penetration. Beilstein J Nanotechnol 2019;10:2280-2293.

152. Ong V, Mei V, Cao L, Lee K, Chung EJ. Nanomedicine for cystic fibrosis. SLAS Technol 2019;24:169-80.

153. Velino C, Carella F, Adamiano A, Sanguinetti N, Vitali A, Catalucci D, et al. Nanomedicine approaches for the pulmonary treatment of cystic fibrosis. Front Bioeng Biotechnol 2019;7:406.

154. Sahu I, Haque AKMA, Weidensee B, Weinmann P, Kormann MSD. Recent developments in mRNA-based protein supplementation therapy to target lung diseases. Mol Ther 2019;27:803-23.

155. Translate Bio, Inc. Translate Bio announces interim results from phase 1/2 clinical trial of MRT5005 in patients with cystic fibrosis, 2019. Available from: http://investors. translate.bio/ node $/ 7101 / \mathrm{pdf}$

156. Marangi M, Pistritto G. Innovative therapeutic strategies for cystic fibrosis: moving forward to CRISPR technique. Front Pharmacol 2018;9:396.

157. Hsu PD, Lander ES, Zhang F. Development and applications of CRISPR-Cas9 for genome engineering. Cell 2014; 157:1262-78.

158. Hille F, Charpentier E. CRISPR-Cas: biology, mechanisms and relevance. Philos Trans R Soc Lond B Biol Sci 2016;371: 20150496.

159. Hodges CA, Conlon RA. Delivering on the promise of gene editing for cystic fibrosis. Genes Dis 2019;6:97-108.

160. Suzuki S, Chosa K, Lee A, Yezzi M, Kai H, Gruenert D. Seamless correction by donor DNA of a class I CFTR mutation facilitated by a double nicking CRISPR/Cas9 in CF-iPSCs. Mol Therapy 2016;24:S51

161. Park J, Bae S. Cpf1-database: web-based genome-wide guide RNA library design for gene knockout screens using CRISPRCpf1. Bioinformatics 2017;34:1077-79.

162. Ledford H. Alternative CRISPR system could improve genome editing. Nature 2015;526:17.

163. Zhang Y, Long C, Li H, McAnally JR, Baskin KK, Shelton JM et al. CRISPR-Cpf1 correction of muscular dystrophy mutations in human cardiomyocytes and mice. Sci Adv 2017;3:e1602814.

164. Maule G, Casini A, Montagna C, Ramalho AS, De Boeck K, Debyser Z, et al. Allele specific repair of splicing mutations in cystic fibrosis through AsCas12a genome editing. Nat Commun 2019;10:3556. Author Correction in: Nat Commun 2020;11:5457.

165. Katz MG, Fargnoli AS, Bridges CR. Myocardial gene transfer: routes and devices for regulation of transgene expression by modulation of cellular permeability. Hum Gene Ther 2013;24:375-92. 